\title{
PID Controller Design for Specified Performance
}

\author{
Štefan Bucz and Alena Kozáková \\ Institute of Control and Industrial Informatics, \\ Faculty of Electrical Engineering and Information Technology, \\ Slovak University of Technology, Bratislava \\ Slovak Republic
}

\section{Introduction}

„How can proper controller adjustments be quickly determined on any control application?" The question posed by authors of the first published PID tuning method J.G.Ziegler and N.B.Nichols in 1942 is still topical and challenging for control engineering community. The reason is clear: just every fifth controller implemented is tuned properly but in fact:

- $30 \%$ of improper performance is due to inadequate selection of controller design method,

- $30 \%$ of improper performance is due to neglected nonlinearities in the control loop,

- $20 \%$ of improper closed-loop dynamics is due to poorly selected sampling period.

Although there are 408 various sources of PID controller tuning methods (O'Dwyer, 2006), $30 \%$ of controllers permanently operate in manual mode and $25 \%$ use factory-tuning without any up-date with respect to the given plant $(\mathrm{Yu}, 2006)$. Hence, there is natural need for effective PID controller design algorithms enabling not only to modify the controlled variable but also achieve specified performance (Kozáková et al., 2010), (Osuský et al., 2010). The chapter provides a survey of 51 existing practice-oriented methods of PID controller design for specified performance. Various options for design strategy and controller structure selection are presented along with PID controller design objectives and performance measures. Industrial controllers from ABB, Allen\&Bradley, Yokogawa, FischerRosemont commonly implement built-in model-free design techniques applicable for various types of plants; these methods are based on minimum information about the plant obtained by the well-known relay experiment. Model-based PID controller tuning techniques acquire plant parameters from a step-test; useful tuning formulae are provided for commonly used system models (FOPDT - first-order plus dead time, IPDT - integrator plus dead time, FOLIPDT - first-order lag and integrator plus dead time and SOPDT second-order plus dead time). Optimization-based PID tuning approaches, tuning methods for unstable plants, and design techniques based on a tuning parameter to continuously modify closed-loop performance are investigated. Finally, a novel advanced design technique based on closed-loop step response shaping is presented and discussed on illustrative examples. 


\section{PID controller design for performance}

Time response of the controlled variable $\mathrm{y}(\mathrm{t})$ is modifiable by tuning proportional gain $\mathrm{K}$, and integrating and derivative time constants $T_{i}$ and $T_{d}$, respectively; the objective is to achieve a zero steady-state control error $\mathrm{e}(\mathrm{t})$ irrespective if caused by changes in the reference $\mathrm{w}(\mathrm{t})$ or the disturbance $\mathrm{d}(\mathrm{t})$. This section presents practice-oriented PID controller design methods based on various perfomance criteria. Consider the control-loop in Fig. 1 with control action $\mathrm{u}(\mathrm{t})$ generated by a PID controller (switch SW in position "1").

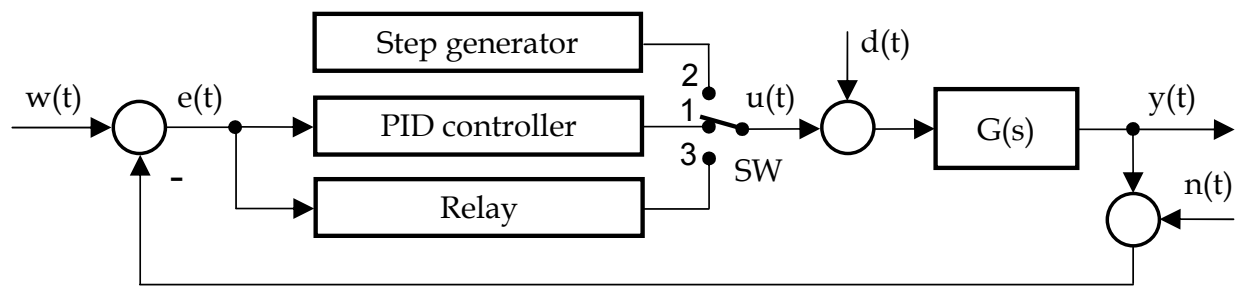

Fig. 1. Feedback control-loop with load disturbance $d(t)$ and measurement noise $n(t)$

A controller design is a two-step procedure consisting of controller structure selection (P, PI, PD or PID) followed by tuning coefficients of the selected controller type.

\subsection{Selection of PID controller structure}

Appropriate structure of the controller $G_{R}(s)$ is usually selected with respect to zero steadystate error condition $(\mathrm{e}(\infty)=0)$, type, and parameters of the controlled plant.

\subsubsection{Controller structure selection based on zero steady-state error condition}

Consider the feedback control loop in Fig. 1 where $G(s)$ is the plant transfer function. According to the Final Value Theorem, the steady-state error

$$
e(\infty)=\lim _{s \rightarrow 0} s E(s)=\lim _{s \rightarrow 0} s \frac{1}{1+L(s)} W(s)=q ! w_{q} \lim _{s \rightarrow 0} \frac{s^{v-q}}{s^{v}+K_{L}}
$$

is zero if in the open-loop $L(s)=G(s) G_{R}(s)$, the integrator degree $v_{L}=v_{S}+v_{R}$ is greater than the degree $q$ of the reference signal $w(t)=w_{q} t q$, i.e.

$$
v_{L}>q
$$

where $v_{S}$ and $v_{R}$ are integrator degrees of the plant and controller, respectively, $\mathrm{K}_{\mathrm{L}}$ is openloop gain and $\mathrm{w}_{\mathrm{q}}$ is a positive constant (Harsányi et al., 1998).

\subsubsection{Principles of controller structure selection based on the plant type}

Industrial process variables (e.g. position, speed, current, temperature, pressure, humidity, level etc.) are commonly controlled using PI controllers. In practice, the derivative part is usually switched off due to measurement noise. For pressure and level control in gas tanks, using P controller is sufficient (Bakošová \& Fikar, 2008). However, adding derivative part improves closed-loop stability and steepens the step response rise (Balátě, 2004). 


\subsubsection{PID controller structure selection based on plant parametres}

Consider the FOPDT $(\mathrm{j}=1)$ and FOLIPDT $(\mathrm{j}=3)$ plant models given as $\mathrm{G}_{\mathrm{FOPDT}}=\mathrm{K}_{1} \mathrm{e}^{-\mathrm{D}_{1} \mathrm{~s}} /\left[\mathrm{T}_{1} \mathrm{~s}+1\right]$ and $\mathrm{G}_{\mathrm{FOLIPDT}}=\mathrm{K}_{3} \mathrm{e}^{-} \mathrm{D}_{3} \mathrm{~s} /\left\{\mathrm{s}\left[\mathrm{T}_{3} \mathrm{~s}+1\right]\right\}$ with following parameters

$$
\tau_{1}=\frac{D_{1}}{T_{1}} ; \quad \rho_{1}=K_{1} K_{c} ; \quad \tau_{3}=\frac{D_{3}}{T_{3}} ; \quad \rho_{3}=\frac{\lim _{s \rightarrow 0} s G(s)}{\omega_{c}\left|G\left(j \omega_{c}\right)\right|}=\frac{T_{c} K_{3} K_{c}}{2 \pi} ; \tau_{3}=\frac{\frac{2}{\pi}+\operatorname{arctg} \sqrt{\rho_{3}^{2}-1}}{\sqrt{\rho_{3}^{2}-1}}
$$

where $K_{c}$ and $\omega_{c}$ are critical gain and frequency of the plant, respectively. Normed time delay $\tau_{\mathrm{j}}$ and parameter $\rho_{\mathrm{j}}$ can be used to select appropriate PID control strategy. According to Tab. 1 (Xue et al., 2007), the derivative part is not used in presence of intense noise and a PID controller is not appropriate for plants with large time delays.

\begin{tabular}{|c|c|c|c|c|}
\hline \multirow[b]{2}{*}{ Ranges for $\tau$ and $\rho$} & \multirow{2}{*}{$\begin{array}{c}\text { No precise } \\
\text { control } \\
\text { necessary }\end{array}$} & \multicolumn{3}{|c|}{ Precise control needed } \\
\hline & & $\begin{array}{l}\text { High } \\
\text { noise }\end{array}$ & $\begin{array}{c}\text { Low } \\
\text { saturation }\end{array}$ & $\begin{array}{l}\text { Low measu- } \\
\text { rement noise }\end{array}$ \\
\hline$\tau_{1}>1 ; \rho_{1}<1,5$ & I & $\mathrm{I}+\mathrm{B}+\mathrm{C}$ & $\mathrm{PI}+\mathrm{B}+\mathrm{C}$ & $\mathrm{PI}+\mathrm{B}+\mathrm{C}$ \\
\hline $0,6<\tau_{1}<1 ; 1,5<\rho_{1}<2,25$ & I or PI & $\mathrm{I}+\mathrm{A}$ & $\mathrm{PI}+\mathrm{A}$ & $(\mathrm{PI}$ or $\mathrm{PID})+\mathrm{A}+\mathrm{C}$ \\
\hline $0,15<\tau_{1}<0,6 ; 2,25<\rho_{1}<15$ & PI & PI & PI or PID & PID \\
\hline$\tau_{1}<0,15 ; \rho_{1}>15$ or $\tau_{3}>0,3 ; \rho_{3}<2$ & P or PI & PI & PI or PID & PI or PID \\
\hline$\tau_{3}<0,3 ; \rho_{3}>2$ & $P D+E$ & $\mathrm{~F}$ & PD+E & $\mathrm{PD}+\mathrm{E}$ \\
\hline
\end{tabular}

Table 1. Controller structure selection with respect to plant model parameters:

A: forward compensation suggested, B: forward compensation necessary, C: dead-time compensation suggested, D: dead-time compensation necessary, E: set-point weighing necessary, F: pole-placement

\subsection{PID controller design objectives}

Consider the following most frequently used PID controller types: ideal PID (4a), real interaction PID with derivative filtering (4b) and ideal PID in series with a first order filter (4c)

$$
G_{R}(s)=K\left(1+\frac{1}{T_{i} s}+T_{d} s\right) ; G_{R}(s)=K\left(1+\frac{1}{T_{i} s}+\frac{T_{d} s}{1+\frac{T_{d}}{N} s}\right) ; G_{R}(s)=K\left(1+\frac{1}{T_{i} s}+T_{d} s\right)\left(\frac{1}{T_{f} s+1}\right)
$$

In practical cases $\mathrm{N} \in\langle 8 ; 16\rangle$ (Visoli, 2006). The PID controller design objectives are:

1. tracking of setpoint or reference variable $\mathrm{w}(\mathrm{t})$ by $\mathrm{y}(\mathrm{t})$,

2. rejection of disturbance $d(t)$ and noise $n(t)$ influence on the controlled variable $y(t)$.

The first objective called also "servo-tuning" is frequent in motion systems (e.g. tracking required speed); techniques to guarantee the second objective are called "regulator-tuning“.

\subsection{Performance measures in the time domain}

Performance measures indicating satisfactory quality of setpoint tracking (Fig. 2a) and disturbance rejection (Fig. 2b) are small maximum overshoot and small decay ratio, respectively, given as 


$$
\eta_{\max }=100 \frac{\left|y_{\max }-y(\infty)\right|}{y(\infty)}[\%] ; \quad \delta_{D R}=\frac{A_{i+1}}{A_{i}}
$$

where $y(\infty)$ denotes steady state of $y(t)$. The ratio of two successive amplitudes $A_{i+1} / A_{i}$ is measure of $y(t)$ decaying, where $i=1 \ldots N$, and $N$ is half of the number of $y(\infty)$ crossings by $y(t)$ (Fig. 2b). A time-domain performance measure is the settling time $t_{s}$, i.e. the time after which the output $y(t)$ remains within $\pm \varepsilon \%$ of its final value (Fig. 2a); typically $\varepsilon=[1 \% \div 5 \%] \mathrm{y}(\infty), \quad \delta_{\mathrm{DR}} \in(1: 4 ; 1: 2), \quad \eta_{\max } \in(0 \% ; 50 \%)$. Fig. 2c depicts underdamped (curve 1$)$, overdamped (curve 2) and critically damped (curve 3) closed-loop step responses.
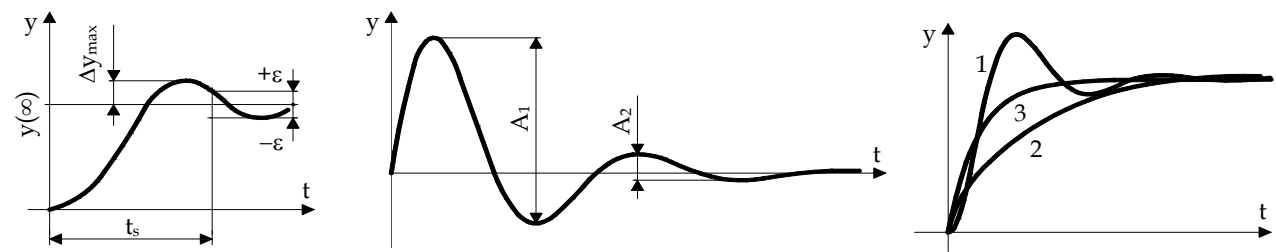

Fig. 2. Performance measures: $\delta_{D R}, t_{s}, \eta_{\max }$ and $(\infty)$; a) setpoint step response; b) load disturbance step response; c) over-, critically- and underdamped closed-loop step-responses

\subsection{Model-free PID controller design techniques with guaranteed performance}

Model-free tuning PID controller techniques are used if plant dynamics is not complicated (without oscillations, vibrations, large overshoots) or if plant modelling is time demanding, uneconomical or even unfeasible. To find PID controller coefficients, instead of a full model usually 2-4 characteristic plant parameters are used obtained from the relay test.

\subsubsection{Tuning rules based on critical parameters of the plant}

Consider the closed-loop in Fig. 1 with proportional controller. If the controller gain $\mathrm{K}$ is successively increased until the process variable oscillates with constant amplitudes, critical parameters can be specified: the period of oscillations $T_{c}$ and the corresponding gain $\mathrm{K}_{\mathrm{c}}$. If the controller (4a) is considered, coefficients of P, PI and PID controllers are calculated according to Tab. 2 , where $\omega_{\mathrm{c}}=2 \pi / \mathrm{T}_{\mathrm{c}}$ is critical frequency of the plant.

\begin{tabular}{|l|l|l|l|l|l|l|}
\hline No. & Design method, year & $\begin{array}{l}\text { Cont- } \\
\text { roller }\end{array}$ & $\mathrm{K}$ & $\mathrm{T}_{\mathrm{i}}$ & $\mathrm{T}_{\mathrm{d}}$ & $\begin{array}{l}\text { Performance or } \\
\text { response }\end{array}$ \\
\hline 1. & (Ziegler \& Nichols, 1942) & $\mathrm{P}$ & $0,5 \mathrm{~K}_{\mathrm{c}}$ & - & - & Quarter decay ratio \\
\hline 2. & (Ziegler \& Nichols, 1942) & PI & $0,45 \mathrm{~K}_{\mathrm{c}}$ & $0,8 \mathrm{~T}_{\mathrm{c}}$ & - & Quarter decay ratio \\
\hline 3. & (Ziegler \& Nichols, 1942) & PID & $0,6 \mathrm{~K}_{\mathrm{c}}$ & $0,5 \mathrm{~T}_{\mathrm{c}}$ & $0,125 \mathrm{~T}_{\mathrm{c}}$ & Quarter decay ratio \\
\hline 4. & (Pettit \& Carr, 1987) & PID & $\mathrm{K}_{\mathrm{c}}$ & $0,5 \mathrm{~T}_{\mathrm{c}}$ & $0,125 \mathrm{~T}_{\mathrm{c}}$ & Underdamped \\
\hline 5. & (Pettit \& Carr, 1987) & PID & $0,67 \mathrm{~K}_{\mathrm{c}}$ & $\mathrm{T}_{\mathrm{c}}$ & $0,167 \mathrm{~T}_{\mathrm{c}}$ & Critically damped \\
\hline 6. & (Pettit \& Carr, 1987) & PID & $0,5 \mathrm{~K}_{\mathrm{c}}$ & $1,5 \mathrm{~T}_{\mathrm{c}}$ & $0,167 \mathrm{~T}_{\mathrm{c}}$ & Overdamped \\
\hline 7. & (Chau, 2002) & PID & $0,33 \mathrm{~K}_{\mathrm{c}}$ & $0,5 \mathrm{~T}_{\mathrm{c}}$ & $0,333 \mathrm{~T}_{\mathrm{c}}$ & Small overshoot \\
\hline 8. & (Chau, 2002) & PID & $0,2 \mathrm{~K}_{\mathrm{c}}$ & $0,55 \mathrm{~T}_{\mathrm{c}}$ & $0,333 \mathrm{~T}_{\mathrm{c}}$ & Without overshoot \\
\hline 9. & $($ Bucz, 2011) & PID & $0,54 \mathrm{~K}_{\mathrm{c}}$ & $0,79 \mathrm{~T}_{\mathrm{c}}$ & $0,199 \mathrm{~T}_{\mathrm{c}}$ & Overshoot $\eta_{\max } \leq 20 \%$ \\
\hline 10. & (Bucz, 2011) & PID & $0,28 \mathrm{~K}_{\mathrm{c}}$ & $1,44 \mathrm{~T}_{\mathrm{c}}$ & $0,359 \mathrm{~T}_{\mathrm{c}}$ & Settling time $\mathrm{t}_{\mathrm{s}} \leq 13 / \omega_{\mathrm{c}}$ \\
\hline
\end{tabular}

Table 2. Controller tuning based on critical parametres of the plant

Rules No. 1 - 3 represent the famous Ziegler-Nichols frequency-domain method with fast rejection of the disturbance $\mathrm{d}(\mathrm{t})$ for $\delta_{\mathrm{DR}}=1: 4$ (Ziegler \& Nichols, 1942). Related methods (No. 
4 - 10) use various weighing of critical parameters thus allowing to vary closed-loop performance requirements. Methods (No. 1 - 10) are applicable for various plant types, easy-to-use and time efficient.

\subsubsection{Specification of critical parameters of the plant using relay experiment}

To quickly determine critical parameters $\mathrm{K}_{\mathrm{c}}$ and $\mathrm{T}_{\mathrm{c}}$, industrial autotuners apply a relay test (Rotach, 1984) either with ideal relay (IR) or a relay with hysteresis (HR). In the loop in Fig. 1 when adjusting the setpoint $\mathrm{w}(\mathrm{t})$ in manual mode and switching $\mathrm{SW}$ into " $3^{\prime \prime}$, a stable limit cycle around $\mathrm{y}(\infty)$ arises. Due to switching between the levels $-\mathrm{M},+\mathrm{M}, \mathrm{G}(\mathrm{s})$ is excited by a periodic rectangular signal $\mathrm{u}(\mathrm{t})$, (Fig. $3 \mathrm{a})$. Then, $\omega_{\mathrm{c}}$ and $\mathrm{K}_{\mathrm{c}}$ can be calculated from

$$
\omega_{c}=\frac{2 \pi}{T_{c}} ; \quad K_{c_{-} I R}=\frac{4 M}{\pi A_{c}} ; K_{c_{-} H R}=\frac{4\left(M-0,5 \Delta_{D B}\right)}{\pi A_{c}}
$$

where the period and amplitude of oscillations $\mathrm{T}_{\mathrm{c}}$ and $\mathrm{A}_{\mathrm{c}}$, respectively, can be obtained from a record of $y(t)$ (Fig. $3 b) ; \Delta_{D B}$ is the width of the hysteresis. Relay amplitude $M$ is usually adjusted at $3 \% \div 10 \%$ of the control action limit. A relay with hysteresis is used if $y(t)$ is corrupted by measurement noise $n(t)(Y u, 2006)$; the critical gain is calculated using (6c).

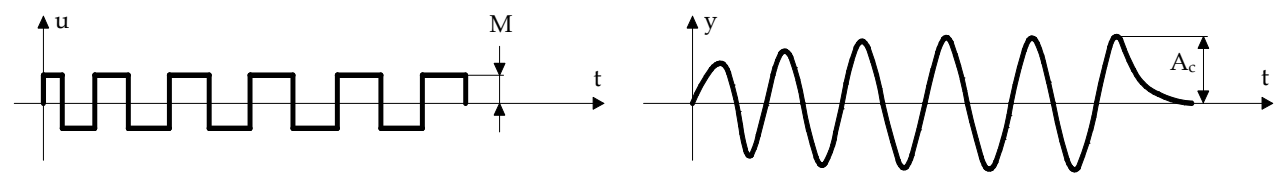

Fig. 3. A detailed view of $u(t)$ and $y(t)$ to determine critical parameters $K_{c}$ and $T_{c}$

\subsection{Model-based PID controller design with guaranteed performance}

Steday-state and dynamic properties of real processes are described by simple FOPDT, IPDT, FOLIPDT or SOPDT models. Model parameters further used to calculate PID controller coefficients can be found e.g. from the plant step responses (Fig. 4 and 5).

\subsubsection{Specification of FOPDT, IPDT and FOLIPDT plant model parameters}

According to Fig. 1, the plant step response is obtained by switching SW into "2" and performing a step change in $\mathrm{u}(\mathrm{t})$. Plant model parameters are obtained by evaluating the particular step response (Fig. 4).
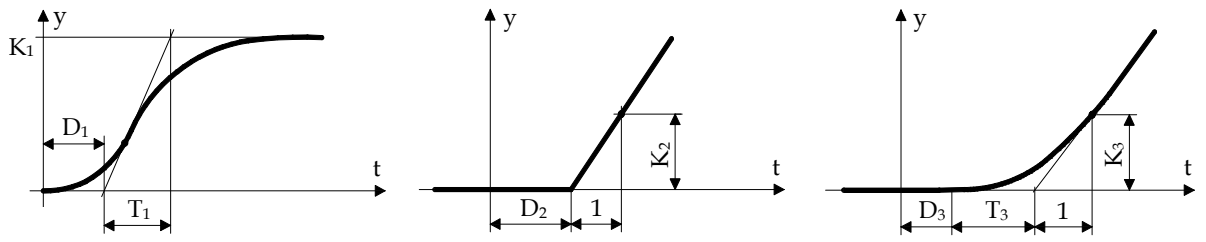

Fig. 4. Typical step responses of a) FOPDT; b) IPDT and c) FOLIPDT models

From the read-off parameters, transfer functions of individual models have been obtained 


$$
G_{F O P D T}(s)=\frac{K_{1} e^{-D_{1} s}}{T_{1} s+1} ; G_{I P D T}(s)=\frac{K_{2} e^{-D_{2} s}}{s} ; G_{F O L I P D T}(s)=\frac{K_{3} e^{-D_{3} s}}{s\left(T_{3} s+1\right)}
$$

\subsubsection{Tuning formulae for FOPDT models}

FOPDT models (7a) are used for chemical processes, thermal systems, manufacturing processes etc. Corresponding P, PI and PID coefficients are calculated using formulae in Tab. 3.

\begin{tabular}{|c|c|c|c|c|c|c|}
\hline No. & $\begin{array}{l}\text { Design method, year, } \\
\text { control purpose }\end{array}$ & $\begin{array}{l}\text { Cont- } \\
\text { roller }\end{array}$ & K & $\mathrm{T}_{\mathrm{i}}$ & $\mathrm{T}_{\mathrm{d}}$ & Performance \\
\hline 11. & \multirow{3}{*}{$\begin{array}{l}\text { (Ziegler \& Nichols, } \\
\text { 1942) }\end{array}$} & $\mathrm{P}$ & $1 / \kappa_{1}$ & - & - & \multirow{3}{*}{$\begin{array}{l}\text { Quarter decay } \\
\text { ratio }\left(\delta_{D R}=1: 4\right)\end{array}$} \\
\hline 12. & & PI & $0,9 / \kappa_{1}$ & $3 \mathrm{D}_{1}$ & - & \\
\hline 13. & & PID & $1,2 / \kappa_{1}$ & $2 \mathrm{D}_{1}$ & $0,5 \mathrm{D}_{1}$ & \\
\hline 14. & \multirow{4}{*}{$\begin{array}{l}\text { (Chien et al., 1952), } \\
\text { Regulator tuning }\end{array}$} & PI & $0,6 / \kappa_{1}$ & $4 \mathrm{D}_{1}$ & - & \multirow{2}{*}{$\begin{array}{l}\eta_{\max }=0 \%, \\
D_{1} / T_{1} \in(0,1 ; 1)\end{array}$} \\
\hline 15. & & PID & $0,95 / \kappa_{1}$ & $2,38 \mathrm{D}_{1}$ & $0,42 \mathrm{D}_{1}$ & \\
\hline 16. & & PI & $0,7 / \kappa_{1}$ & $2,33 \mathrm{D}_{1}$ & - & \multirow{2}{*}{$\begin{array}{l}\eta_{\max }=20 \%, \\
\mathrm{D}_{1} / \mathrm{T}_{1} \in(0,1 ; 1)\end{array}$} \\
\hline 17. & & PID & $1,2 / \kappa_{1}$ & $2 \mathrm{D}_{1}$ & $0,42 \mathrm{D}_{1}$ & \\
\hline 18. & \multirow{4}{*}{$\begin{array}{l}\text { (Chien et al., 1952), } \\
\text { Servo tuning }\end{array}$} & PI & $0,35 / \kappa_{1}$ & $1,17 D_{1}$ & - & \multirow{2}{*}{$\begin{array}{l}\eta_{\max }=0 \%, \\
\mathrm{D}_{1} / \mathrm{T}_{1} \in(0,1 ; 1)\end{array}$} \\
\hline 19. & & PID & $0,6 / \kappa_{1}$ & $\mathrm{D}_{1}$ & $0,5 \mathrm{D}_{1}$ & \\
\hline 20. & & PI & $0,6 / \kappa_{1}$ & $\mathrm{D}_{1}$ & - & \multirow{2}{*}{$\begin{array}{l}\eta_{\max }=20 \%, \\
D_{1} / T_{1} \in(0,1 ; 1)\end{array}$} \\
\hline 21. & & PID & $0,95 / \kappa_{1}$ & $1,36 \mathrm{D}_{1}$ & $0,47 \mathrm{D}_{1}$ & \\
\hline 22. & \multirow{2}{*}{$\begin{array}{l}\text { (ControlSoft Inc., } \\
\text { 2005) }\end{array}$} & PID & $2 / \mathrm{K}_{1}$ & $\mathrm{~T}_{1}+\mathrm{D}_{1}$ & $\max \left(\mathrm{D}_{1} / 3 ; \mathrm{T}_{1} / 6\right)$ & Slow loop \\
\hline 23. & & PID & $2 / K_{1}$ & $\mathrm{~T}_{1}+\mathrm{D}_{1}$ & $\min \left(\mathrm{D}_{1} / 3 ; \mathrm{T}_{1} / 6\right)$ & Fast loop \\
\hline
\end{tabular}

Table 3. PID tuning rules based on FOPDT model; $\kappa_{1}=K_{1} D_{1} / T_{1}$ is the normed process gain

Formulae No. 11 - 13 represent the time-domain (or reaction curve) Ziegler-Nichols method (Ziegler \& Nichols, 1942) and usually give higher open-loop gains than the frequencydomain version. Algorithms by Chien-Hrones-Reswick provide different settings for setpoint regulation and disturbance rejection for two representative maximum overshoot values.

\subsubsection{Tuning formulae for IPDT and FOLIPDT models}

While dynamics of slow industrial processes (polymer production, heat exchangers) can be described by IPDT model $(7 \mathrm{~b})$, electromechanic subsystems of turning machines and servodrives are typical examples for using FOLIPDT model (7c).

\begin{tabular}{|l|l|l|l|l|l|l|}
\hline No. & Design method, year, model & $\begin{array}{l}\text { Cont- } \\
\text { roller }\end{array}$ & $\mathrm{K}$ & $\mathrm{T}_{\mathrm{i}}$ & $\mathrm{T}_{\mathrm{d}}$ & $\begin{array}{l}\text { Perfor- } \\
\text { mance }\end{array}$ \\
\hline 24. & (Haalman, 1965), IPDT & $\mathrm{P}$ & $0,66 /\left(\mathrm{K}_{2} \mathrm{D}_{2}\right)$ & - & - & $\mathrm{M}_{\mathrm{s}}=1,9$ \\
\hline 25. & (Ziegler \& Nichols, 1942), IPDT & $\mathrm{PI}$ & $0,9 /\left(\mathrm{K}_{2} \mathrm{D}_{2}\right)$ & $3,33 \mathrm{D}_{2}$ & - & $\delta_{\mathrm{DR}}=1: 4$ \\
\hline 26. & (Ford, 1953), IPDT & $\mathrm{PID}$ & $1,48 /\left(\mathrm{K}_{2} \mathrm{D}_{2}\right)$ & $2 \mathrm{D}_{2}$ & $0,37 \mathrm{D}_{2}$ & $\delta_{\mathrm{DR}}=1: 2,7$ \\
\hline 27. & (Coon, 1956), FOLIPDT & $\mathrm{P}$ & $\mathrm{x}_{3} /\left[\mathrm{K}_{3}\left(\mathrm{D}_{3}+\mathrm{T}_{3}\right)\right]$ & - & - & $\delta_{\mathrm{DR}}=1: 4$ \\
\hline 28. & (Haalman, 1965), FOLIPDT & $\mathrm{PD}$ & $0,66 /\left(\mathrm{K}_{3} \mathrm{D}_{3}\right)$ & - & $\mathrm{T}_{3}$ & $\mathrm{M}_{\mathrm{s}}=1,9$ \\
\hline
\end{tabular}

Table 4. Tuning rules based on IPDT and FOLIPDT model parameters 
According to Haalman (rules No. 24 and 28), controller transfer function $G_{R}(s)=L(s) / G(s)$, where $\mathrm{L}(\mathrm{s})=0,66 \mathrm{e}^{-\mathrm{Ds}} /(\mathrm{Ds})$ is the ideal loop transfer function guaranteeing maximum closedloop sensitivity $M_{s}=1,9$ to disturbance $d(t)$, (see subsection 2.8.1). For various $G(s)$, various controller structures are obtained. The gain K in rule No. 27 depends on the normed time delay $v_{3}=D_{3} / T_{3}$ of the FOLIPDT model; for corresponding couples hold: $\left(v_{3} ; x_{3}\right)=\{(0,02 ; 5)$, $(0,053 ; 4) ;(0,11 ; 3) ;(0,25 ; 2,2) ;(0,43 ; 1,7) ;(1 ; 1,3) ;(4 ; 1,1)\}$. Due to integrator contained in IPDT and FOLIPDT models, I-term in the controller structure is needed just to achieve zero steady-state error $\mathrm{e}(\infty)$ under steady-state disturbance $\mathrm{d}(\infty)$.

\subsubsection{Tuning formulae for SOPDT plant models}

Flexible systems in wood processing industry, automotive industry, robotis, shocks and vibrations damping are often modelled by SOSPTD models with transfer functions

$$
G_{S O P D T}(s)=\frac{K_{4} e^{-D_{4} s}}{\left(T_{4} s+1\right)\left(T_{5} s+1\right)} ; G_{S O P D T}(s)=\frac{K_{6} e^{-D_{6} s}}{T_{6}^{2} s^{2}+2 \xi_{6} T_{6} s+1}
$$

For SOPDT model $(8 b)$, the relative damping $\xi_{6} \in(0 ; 1)$ indicates oscillatory step response.
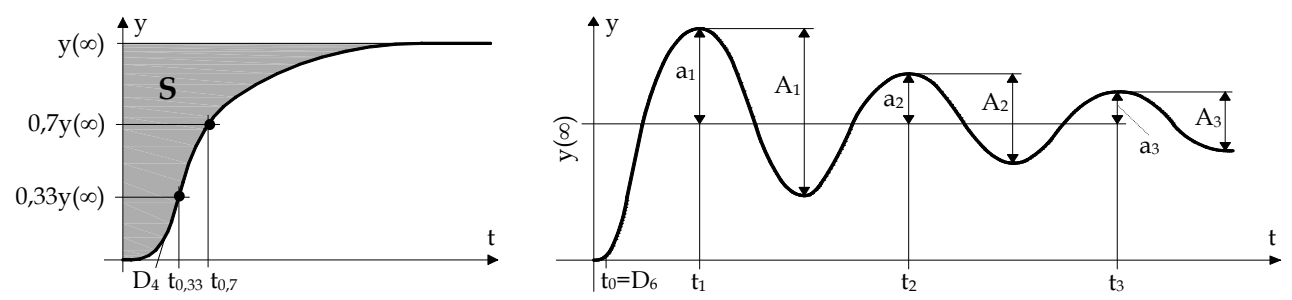

Fig. 5. Step response of SOPDT model: a) non-oscillatory, b) oscillatory

If $\xi_{6}>1$, SOPDT model (8a) is used; its parameters are found from the non-oscillatory step response in Fig. 5a using the following relations

$$
T_{4,5}=\frac{1}{2}\left(C_{2} \pm \sqrt{C_{2}^{2}-4 C_{1}^{2}}\right) ; D_{4}=\frac{t_{0,33}}{0,516}-\frac{t_{0,7}}{1,067} ; \quad C_{1}=\frac{\left(t_{0,33}-t_{0,7}\right)}{1,259} ; C_{2}=\frac{S}{y(\infty)}-D_{4}
$$

where $S=K_{4}\left(T_{4}+T_{5}+D_{4}\right)$ denotes the area above the step response of $y(t)$, and $y(\infty)$ is its steady-state value. Parameters of the SOPDT model $(8 \mathrm{~b})$ can be found from evaluation of 2-4 periods of step response oscillations (Fig. 5b) using following rules (Vítečková, 1998)

$$
\xi_{6}=\frac{-\ln \frac{a_{i+1}}{a_{i}}}{\sqrt{\pi^{2}+\ln ^{2} \frac{a_{i+1}}{a_{i}}}} ; T_{6}=\frac{\sqrt{1-\xi_{6}^{2}}}{\pi N}\left(t_{N+1}-t_{1}\right) ; D_{6}=\frac{1}{N}\left[\sum_{i=1}^{N} t_{i}-\frac{N+1}{2}\left(t_{N+1}-t_{1}\right)\right]
$$

Quality of identification improves with increasing number of read-off amplitudes N. If $N>2$ several values $\xi_{6}, \mathrm{~T}_{6}$ and $\mathrm{D}_{6}$ are obtained and their average is taken for further calculations. Tab. 5 summarizes useful tuning formulae for both oscillatory and non-oscillatory systems with SOPDT model properties. 


\begin{tabular}{|c|c|c|c|c|c|c|}
\hline No. & $\begin{array}{l}\text { Method, } \\
\text { year }\end{array}$ & $\begin{array}{l}\text { Cont- } \\
\text { roller }\end{array}$ & K & $\mathrm{T}_{\mathrm{i}}$ & $\mathrm{T}_{\mathrm{d}}$ & Performance for \\
\hline 29. & $\begin{array}{l}\text { (Suyama, } \\
1992)\end{array}$ & PID & $\frac{T_{4}+T_{5}}{2 K_{4} D_{4}}$ & $\mathrm{~T}_{4}+\mathrm{T}_{5}$ & $\frac{T_{4} T_{5}}{T_{4}+T_{5}}$ & $\begin{array}{l}\text { Closed-loop step response } \\
\text { overshoot } \eta_{\max }=10 \%\end{array}$ \\
\hline 30. & $\begin{array}{l}\text { Vítečková, } \\
(1999),\end{array}$ & PID & $x_{4} \frac{T_{4}+T_{5}}{K_{4} D_{4}}$ & $\mathrm{~T}_{4}+\mathrm{T}_{5}$ & $\frac{T_{4} T_{5}}{T_{4}+T_{5}}$ & $\begin{array}{l}\text { Overdamped plants; } \mathrm{T}_{5}>\mathrm{T}_{4} \\
\eta_{\max }=0 \%: \mathrm{x}_{4}=0,368 \\
\eta_{\max }=30 \%: \mathrm{x}_{4}=0,801\end{array}$ \\
\hline 31. & $\begin{array}{l}\text { Vítečková } \\
\text { et al., (2000) }\end{array}$ & PID & $\frac{x_{6} \xi_{6} T_{6}}{K_{6} D_{6}}$ & $2 \xi_{6} \mathrm{~T}_{6}$ & $\frac{T_{6}}{2 \xi_{6}}$ & $\begin{array}{l}\text { Underdamped plants }\left(0,5<\xi_{6} \leq 1\right) \\
\eta_{\max }=0 \%: x_{6}=0,736 \\
\eta_{\max }=30 \%: x_{6}=1,602\end{array}$ \\
\hline 32. & $\begin{array}{l}(\text { Wang \& } \\
\text { Shao, 1999) }\end{array}$ & PID & $\frac{x_{6} \xi_{6} T_{6}}{K_{6} D_{6}}$ & $2 \xi_{6} \mathrm{~T}_{6}$ & $\frac{T_{6}}{2 \xi_{6}}$ & $\begin{array}{l}{\left[\mathrm{G}_{\mathrm{M}}=2, \phi_{\mathrm{M}}=45^{\circ}\right]: \mathrm{x}_{6}=1,571} \\
{\left[\mathrm{G}_{\mathrm{M}}=5, \phi_{\mathrm{M}}=72^{\circ}\right]: \mathrm{x}_{6}=0,628}\end{array}$ \\
\hline 33. & $\begin{array}{l}\text { (Chen } \\
\text { et al., 1999) }\end{array}$ & PID & $\frac{x_{6} \xi_{6} T_{6}}{K_{6} D_{6}}$ & $2 \xi_{6} \mathrm{~T}_{6}$ & $\frac{D_{6}}{2 \xi_{6}}$ & $\begin{array}{l}{\left[\mathrm{G}_{\mathrm{M}} ; \phi_{\mathrm{M}} ; \mathrm{M}_{\mathrm{S}}\right]=\left[3,14 ; 61,4^{\circ} ; 1\right]: \mathrm{x}_{6}=1,0} \\
{\left[\mathrm{G}_{\mathrm{M}} ; \phi_{\mathrm{M}} ; \mathrm{M}_{\mathrm{S}}\right]=\left[1,96 ; 44,1^{\circ} ; 1,5\right]: \mathrm{x}_{6}=1,6}\end{array}$ \\
\hline
\end{tabular}

Table 5. Tuning rules based on SOPDT model parameters

\subsection{PID controller design based on optimization techniques}

Optimal PID controller tuning can be found by minimizing the performance index

$$
I\left(K, T_{i}, T_{d}\right)=\int_{0}^{\infty}\left[t^{n} e\left(K, T_{i}, T_{d}, t\right)\right]^{2} d t
$$

Its particular cases are known as integral square error (ISE) for $n=0$; integral squared time weighed error (ISTE) for $n=1$, and integral squared time-squared weighed error (IST2 $E$ ) for $\mathrm{n}=2$. Some tuning formulae for PID controller in form (4a) are shown in Tab. 6. Settling time $t_{s}$ in rules No. 40 and 41 is affected by $D_{2}$.

\begin{tabular}{|c|c|c|c|c|c|}
\hline No. & Method, year, model & K & $\mathrm{T}_{\mathrm{i}}$ & $\mathrm{T}_{\mathrm{d}}$ & Performance \\
\hline 34. & \multirow{3}{*}{$\begin{array}{l}\text { (Zhuang \& Atherton, } \\
\text { 1993), FOPDT model, } \\
v_{1} \in\langle 0,1 ; 1\rangle\end{array}$} & $1,473 v_{1}^{0,970} / K_{1}$ & $0,897 \mathrm{~T}_{1} \mathrm{v}_{1} 0,753$ & $0,550 \mathrm{~T}_{1} v_{1}{ }^{0,948}$ & Minimum ISE \\
\hline 35. & & $1,468 v_{1} 0,970 / K_{1}$ & $1,062 \mathrm{~T}_{1} \mathrm{v}_{1} 0,725$ & $0,443 \mathrm{~T}_{1} v_{1} 0,939$ & Minimum ISTE \\
\hline 36. & & $1,531 v_{1}{ }^{0,960} / \mathrm{K}_{1}$ & $1,030 \mathrm{~T}_{1} \mathrm{v}_{1}{ }^{0,746}$ & $0,413 \mathrm{~T}_{1} \mathrm{v}_{1} 0,933$ & Minimum IST22 $\mathrm{E}$ \\
\hline 37. & \multirow{3}{*}{$\begin{array}{l}\text { (Zhuang \& Atherton, } \\
\text { 1993), FOPDT model, } \\
v_{1} \in\langle 1,1 ; 2\rangle\end{array}$} & $1,524 v_{1} 0,735 / K_{1}$ & $0,885 \mathrm{~T}_{1} \mathrm{v}_{1} 0,641$ & $0,552 \mathrm{~T}_{1} \mathrm{v}_{1} 0,851$ & Minimum ISE \\
\hline 38. & & $1,515 v_{1}{ }^{0,730} / K_{1}$ & $1,045 \mathrm{~T}_{1} \mathrm{v}_{1} 0,598$ & $0,444 \mathrm{~T}_{1} \mathrm{v}_{1} \mathrm{v}^{0,847}$ & Minimum ISTE \\
\hline 39. & & $1,592 v_{1} 0,705 / K_{1}$ & $1,045 \mathrm{~T}_{1} \mathrm{v}_{1} 0,597$ & $0,414 \mathrm{~T}_{1} \mathrm{v}_{1} 0,850$ & Minimum IST22 $\mathrm{E}$ \\
\hline 40. & \multirow{2}{*}{$\begin{array}{l}\text { (Wang a Cluett, 1997), } \\
\text { IPDT model }\end{array}$} & $0,9588 /\left[\mathrm{K}_{2} \mathrm{D}_{2}\right]$ & $3,0425 \mathrm{D}_{2}$ & $0,3912 \mathrm{D}_{2}$ & $\mathrm{t}_{\mathrm{s}}=\mathrm{D}_{2}$ \\
\hline 41. & & $0,3144 /\left[\mathrm{K}_{2} \mathrm{D}_{2}\right]$ & $11,1637 \mathrm{D}_{2}$ & $0,1453 \mathrm{D}_{2}$ & $t_{\mathrm{s}}=5 \mathrm{D}_{2}$ \\
\hline
\end{tabular}

Table 6 . Tuning rules based on minimizing performance indices

\subsection{PID controller setting for unstable FOPDT models}

Minimization of performance indices can be applied also for unstable FOPDT models

$$
G_{F O P D T_{-} U S}(s)=\frac{K_{1} e^{-D_{1} s}}{T_{1} s-1}
$$


leading to simple tuning rules for PID controller (4a) (No. $42-44$ in Tab. 7). Tuning rules No. 45 and 46 for PID controller (4c) show that settling time $t_{s}$ increases with growing normed time delay $v_{1}=\mathrm{D}_{1} / \mathrm{T}_{1}$ of the FOPDT model (12).

\begin{tabular}{|c|c|c|c|c|c|c|}
\hline No. & Method, year & $\mathrm{K}$ & $\mathrm{T}_{\mathrm{i}}$ & $\mathrm{T}_{\mathrm{d}}$ & $T_{f}$ & Performance \\
\hline 42. & \multirow{3}{*}{$\begin{array}{l}\text { (Visoli, 2001), } \\
\text { Regulator } \\
\text { tuning }\end{array}$} & $1,37 v_{1} / K_{1}$ & $2,42 \mathrm{~T}_{1} \mathrm{v}_{1}{ }^{1,18}$ & $0,60 \mathrm{~T}_{1}$ & - & Minimum ISE \\
\hline 43. & & $1,37 v_{1} / K_{1}$ & $4,12 \mathrm{~T}_{1} \mathrm{v}_{1} 0,90$ & $0,55 \mathrm{~T}_{1}$ & - & Minimum ISTE \\
\hline 44. & & $1,70 v_{1} / K_{1}$ & $4,52 \mathrm{~T}_{1} \mathrm{v}_{1} 1,13$ & $0,50 \mathrm{~T}_{1}$ & - & Minimum IST22 $\mathrm{E}$ \\
\hline 45. & \multirow{2}{*}{$\begin{array}{l}\text { (Chandrashekar } \\
\text { et al., 2002) }\end{array}$} & $10,3662 / \mathrm{K}_{1}$ & $0,3874 \mathrm{~T}_{1}$ & $0,0435 \mathrm{~T}_{1}$ & $0,0134 \mathrm{~T}_{1}$ & $\mathrm{t}_{\mathrm{s}}=0,1 \mathrm{~T}_{1}: v_{1}=0,1$ \\
\hline 46. & & $2,0217 / K_{1}$ & $4,65 \mathrm{~T}_{1}$ & $0,2366 \mathrm{~T}_{1}$ & $0,0696 \mathrm{~T}_{1}$ & $\mathrm{t}_{\mathrm{s}}=0,8 \mathrm{~T}_{1}: v_{1}=0,5$ \\
\hline
\end{tabular}

Table 7. Tuning rules for unstable FOPDT model

Using tuning methods shown in Tab. $2-7$, achieved performance is a priori given by the chosen metod (e.g. a quarter decay ratio if using Ziegler-Nichols methods No. $11-13$ in Tab. 3), or guaranteed performance however not specified by the designer (e.g. in Chen method No. 33 in Tab. 5, a gain margin $\mathrm{G}_{\mathrm{M}}=1,96$, a phase margin $\phi_{\mathrm{M}}=44,1^{\circ}$, and a maximum peak of the sensitivity to disturbance $\left.d(t) M_{s}=1,5\right)$.

\subsection{PID controller design for specified performance}

These methods provide tuning rules are based on a single tuning parameter that enables to systematically affect closed-loop performance by step response shaping.

\subsubsection{Performance measures used as a PID tuning parameter}

Most frequent parameters for tuning PID controllers are following performance measures (Åström \& Hägglund, 1995):

- $\phi_{\mathrm{M}}$ and $\mathrm{G}_{\mathrm{M}}$ : phase and gain margins, respectively,

- $\mathrm{M}_{\mathrm{s}}$ and $\mathrm{M}_{\mathrm{t}}$ : maximum peaks of sensitivity $\mathrm{S}(\mathrm{j} \omega)$ and complementary sensitivity $\mathrm{T}(\mathrm{j} \omega)$ magnitudes, respectively,

- $\quad \lambda$ : required closed-loop time constant.

If a controller $G_{R}(j \omega)$ guarantees that $|S(j \omega)|$ or $|T(j \omega)|$ do not overrun prespecified values $M_{s}$ or $\mathrm{M}_{\mathrm{t}}$, respectively, defined by

$$
M_{S}=\sup _{\omega}|S(j \omega)|=\sup _{\omega}\left|\frac{1}{1+L(j \omega)}\right| ; \quad M_{t}=\sup _{\omega}|T(j \omega)|=\sup _{\omega}\left|\frac{L(j \omega)}{1+L(j \omega)}\right|
$$

over $\omega \in\langle 0, \infty)$, then the Nyquist plot $L(j \omega)$ of the open-loop $L(s)=G(s) G_{R}(s)$ avoids the respective circle $\mathrm{M}_{\mathrm{S}}$ or $\mathrm{M}_{\mathrm{T}}$, each given by the their center and radius as follows

$$
C_{S}=[-1, j 0], R_{S}=\frac{1}{M_{S}} ; \quad C_{T}=\left[-\frac{M_{t}^{2}}{M_{t}^{2}-1}, j 0\right], R_{T}=-\frac{M_{t}}{\left|1-M_{t}^{2}\right|}
$$

If $\mathrm{L}(\mathrm{j} \omega)$ avoids entering the circles corresponding to $\mathrm{M}_{\mathrm{S}}$ or $\mathrm{M}_{\mathrm{T}}$, a safe distance from the point $\mathrm{C}_{S}$ is kept (Fig. 6a). Typical $|S(j \omega)|$ and $|\mathrm{T}(\mathrm{j} \omega)|$ plots for properly designed controller are plotted in Fig. 6b. The disturbance $d(t)$ is sufficiently rejected if $M_{s} \in(1,2 ; 2)$. The reference $\mathrm{w}(\mathrm{t})$ is properly tracked by the process output $\mathrm{y}(\mathrm{t})$ if $\mathrm{M}_{\mathrm{t}} \in(1,3 ; 2,5)$. With further increasing of $\mathrm{M}_{\mathrm{t}}$ the closed-loop tends to be oscillatory. 

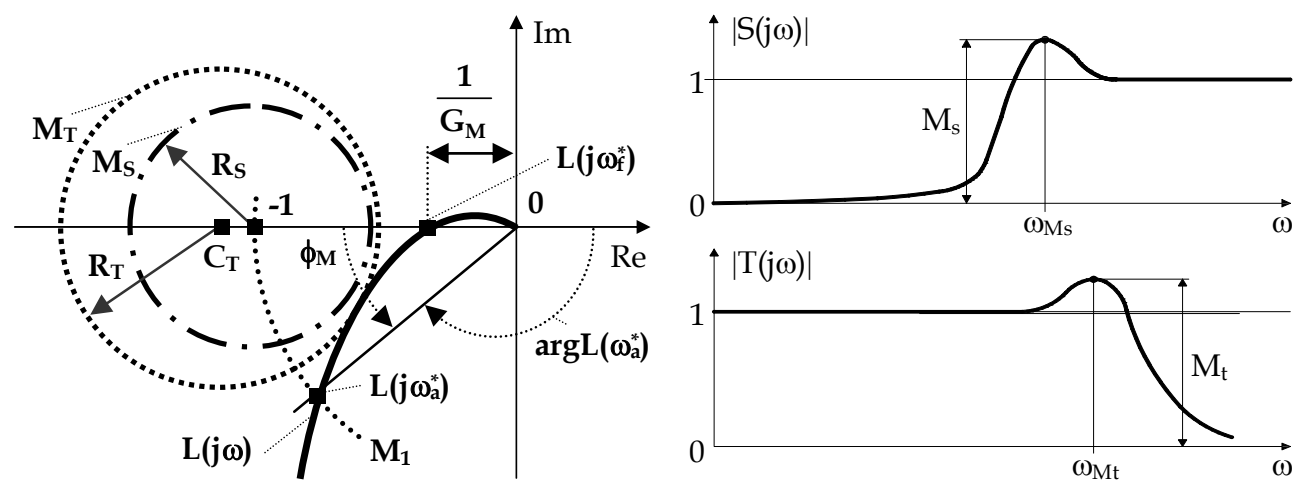

Fig. 6. a) Definition and geometrical interpretation of $\phi_{M}$ and $G_{M}$ in the complex plane;

b) Sensitivity and complementary sensitivity magnitudes $|S(j \omega)|,|T(j \omega)|$ and performance measures $\mathrm{M}_{\mathrm{s}}, \mathrm{M}_{\mathrm{t}}$

From Fig. 6a results, that increasing open-loop phase margin $\phi_{M}$ causes moving the gain crossover $\mathrm{L}\left(\mathrm{j} \omega_{\mathrm{a}}{ }^{*}\right)$ lying on the unit circle $\mathrm{M}_{1}$ away from the critical point $(-1, j 0)$. Increasing open-loop gain margin $G_{M}$ causes moving the phase crossover $L\left(j \omega_{f}^{*}\right)$ away from $(-1, j 0)$. Therefore, parameters $\phi_{M}$ or $G_{M}$ given by

$$
\phi_{M}=180^{\circ}+\arg L\left(\omega_{a}^{*}\right) ; \quad G_{M}=\frac{1}{\left|L\left(j \omega_{f}^{*}\right)\right|}
$$

are frequently used performance measures, their typical values are $\phi_{M} \in\left(20^{\circ} ; 90^{\circ}\right), G_{M} \in(2 ; 5)$. Relations between them are given by following inequalities

$$
\phi_{M} \geq 2 \arcsin \left(\frac{1}{2 M_{s}}\right) ; \quad \phi_{M} \geq 2 \arcsin \left(\frac{1}{2 M_{t}}\right) ; \quad G_{M} \geq \frac{M_{s}}{M_{s}-1} ; \quad G_{M} \geq 1+\frac{1}{M_{t}}
$$

The point at which the Nyquist plot $\mathrm{L}(\mathrm{j} \omega)$ touches the $\mathrm{M}_{\mathrm{T}}$ circle defines the closed-loop resonance frequency $\omega_{\mathrm{Mt}}$.

\subsubsection{Tuning formulae with performance specification}

Table 8 shows open formulae for PID controller design. The coefficients tuning is carried out with respect to closed-loop performance specification. Rules No. 47 - 49 consider tuning of ideal PID controller (4a). To apply the Rotach method, knowledge of the plant magnitude $|G(j \omega)|$ is supposed as well as of the roll-off of $\arg G(\omega)$ at $\omega=\omega_{\mathrm{Mt}}$, where the maximum peak $\mathrm{M}_{\mathrm{t}}$ of the complementary sensitivity is required. Method No. 50 is based on so-called $\lambda$-tuning, with the resulting closed-loop expressed as a $1^{\text {st }}$ order system with time constant $\lambda$; this rule considers a real PID controller $(4 \mathrm{~b})$ with filtering constant in the derivative part $\mathrm{T}_{\mathrm{f}}=\mathrm{T}_{\mathrm{d}} / \mathrm{N}=0,5 \lambda \mathrm{D}_{1} /\left(1+\mathrm{D}_{1}\right)$ where $\lambda$ is to be chosen to meet following conditions: $\lambda>0,25 \mathrm{D}_{1}$; $\lambda>0,25 \mathrm{~T}_{1}$ (Morari \& Zafiriou, 1989). The $\lambda$-tuning technique is used also in the rule No. 51 to design interaction PI controller. 


\begin{tabular}{|c|c|c|c|c|}
\hline No. & $\begin{array}{l}\text { Design method, } \\
\text { year, } \\
\text { model }\end{array}$ & $\mathrm{K}$ & $\mathrm{T}_{\mathrm{i}}$ & $\mathrm{T}_{\mathrm{d}}$ \\
\hline 47. & $\begin{array}{l}\text { (Hang \& Åström, } \\
\text { 1988), } \\
\text { Non-model }\end{array}$ & $\mathrm{K}_{\mathrm{C}} \sin \phi_{\mathrm{M}}$ & $\frac{T_{c}\left(1-\cos \phi_{M}\right)}{\pi \sin \phi_{M}}$ & $\frac{T_{c}\left(1-\cos \phi_{M}\right)}{4 \pi \sin \phi_{M}}$ \\
\hline 48. & $\begin{array}{l}\text { (Rotach, 1994), } \\
\text { Non-model }\end{array}$ & $\frac{M_{t}\left|G\left(j \omega_{M t}\right)\right|}{\sqrt{M_{t}^{2}-1}}$ & $\frac{-2}{\omega_{M t}^{2}\left(\frac{d\left[\arg G\left(\omega_{M t}\right)\right]}{d \omega_{M t}}\right)}$ & $-\frac{1}{2} \frac{d\left[\arg G\left(\omega_{M t}\right)\right]}{d \omega_{M t}}$ \\
\hline 49. & $\begin{array}{l}\text { (Wojsznis } \\
\text { et al., 1999), } \\
\text { FOPDT }\end{array}$ & $\frac{K_{c} \cos \phi_{M}}{G_{M}}$ & $\frac{T_{c}}{\pi}\left(\operatorname{tg} \phi_{M}+\sqrt{1+\operatorname{tg}^{2} \phi_{M}}\right.$ & $\frac{T_{c}}{4 \pi}\left(\operatorname{tg} \phi_{M}+\sqrt{1+\operatorname{tg}^{2} \phi_{M}}\right.$ \\
\hline 50. & \begin{tabular}{|l|} 
(Morari \& Zafiriou, \\
1989), \\
FOPDT
\end{tabular} & $\frac{T_{1}+0,5 D_{1}}{K_{1}\left(\lambda+D_{1}\right)}$ & $T_{1}+\frac{1}{2} D_{1}$ & $\frac{T_{1} D_{1}}{2 T_{1}+D_{1}}$ \\
\hline 51. & \begin{tabular}{|l|} 
(Chen \& Seborg, \\
2002), \\
FOPDT
\end{tabular} & $\frac{T_{1} D_{1}+2 T_{1} \lambda-\lambda^{2}}{K_{1}\left(\lambda+D_{1}\right)^{2}}$ & $\frac{T_{1} D_{1}+2 T_{1} \lambda-\lambda^{2}}{T_{1}+D_{1}}$ & - \\
\hline
\end{tabular}

Table 8. PID design formulae for specified performance based on tuning parameters $\phi_{\mathrm{M}}, \mathrm{G}_{\mathrm{M}}$, $\mathrm{M}_{\mathrm{t}}$ and $\lambda$

\subsubsection{Performance evaluation}

Phase margin $\phi_{\mathrm{M}}$ is the most wide-spread performance measure in PID controller design. Maximum overshoot $\eta_{\max }$ and settling time $t_{\mathrm{s}}$ of the closed-loop step response are related with $\phi_{\mathrm{M}}$ according to Reinisch relations

$$
\eta_{\text {max }}=\left\{\begin{array}{l}
-0,91 \phi_{M}+64,55 \text { for } \phi_{M} \in\left\langle 38^{\circ} ; 71^{\circ}\right\rangle \\
-1,53 \phi_{M}+88,46 \text { for } \phi_{M} \in\left\langle 12^{\circ} ; 38^{\circ}\right\rangle
\end{array} ; \quad \eta_{\max }=100 e^{-2 \pi b^{2} M_{t}} ; t_{s} \in\left(\frac{\pi}{\omega_{a}^{*}}, \frac{4 \pi}{\omega_{a}^{*}}\right)\right.
$$

valid for $2^{\text {nd }}$ order closed-loop with relative damping $\xi \in(0,25 ; 0,65)$ where $\omega_{a}{ }^{*}$ is the gain crossover frequency (Hudzovič, 1982). Relations

$$
\eta_{\max } \leq 100 \frac{1.18 M_{t}-|T(0)|}{|T(0)|}[\%] ; \quad t_{s} \approx \frac{3}{\omega_{a}^{*}} \text { for } M_{t} \in(1,3 ; 1,5)
$$

(Hudzovič, 1982); (Grabbe et al., 1959-61) are general for any order of the closed-loop T(s); if the controller has the integral part then $|\mathrm{T}(0)|=|\mathrm{T}(\omega=0)|=1$.

The engineering practice is persistently demanding for PID controller design methods simultaneously guaranteeing several performance criteria, especially maximum overshoot $\eta_{\max }$ and settling time $t_{s}$. However, we ask the question: how to suitably transform the above-mentioned engineering requirements into frequency domain specifications applicable for PID controller coefficients tuning? The response can be found in Section 3 where a novel original PID controller design method is presented. 


\section{Advanced PID controller design method based on sine-wave identification}

The presented method is applicable for linear stable SISO systems even with unknown mathematical model. The control objective is to provide required maximum overshoot $\eta_{\max }$ and settling time $t_{s}$ of the process variable $y(t)$. The method enables the designer to prescribe $\eta_{\max }$ and $t_{\mathrm{s}}$ within following ranges (Bucz et al., 2010b, 2010c), (Bucz, 2011)

- $\eta_{\max } \in\langle 0 \% ; 90 \%\rangle$ and $t_{s} \in\left\langle 6,5 / \omega_{c} ; 45 / \omega_{c}\right\rangle$ for systems without integrator,

- $\eta_{\max } \in\langle 9,5 \% ; 90 \%\rangle$ and $t_{s} \in\left\langle 11,5 / \omega_{c} ; 45 / \omega_{c}\right\rangle$ for systems with integrator, where $\omega_{\mathrm{c}}$ is the plant critical frequency. The PID controller design provides guaranteed phase margin $\phi_{\mathrm{M}}$. The tuning rule parameter is a suitably chosen point of the plant frequency response obtained by a sine-wave signal with excitation frequency $\omega_{\mathrm{n}}$. The designed controller then moves this point into the gain crossover with the required phase margin $\phi_{\mathrm{M}}$. With respect to engineering requirements, the pair $\left(\omega_{n} ; \phi_{\mathrm{M}}\right)$ is specified on the closed-loop step response in terms of $\eta_{\max }$ and $t_{\mathrm{s}}$ according to parabolic dependencies in Fig. 11 and Fig. 14-16. A multipurpose loop for the proposed sine-wave method is in Fig. 7.

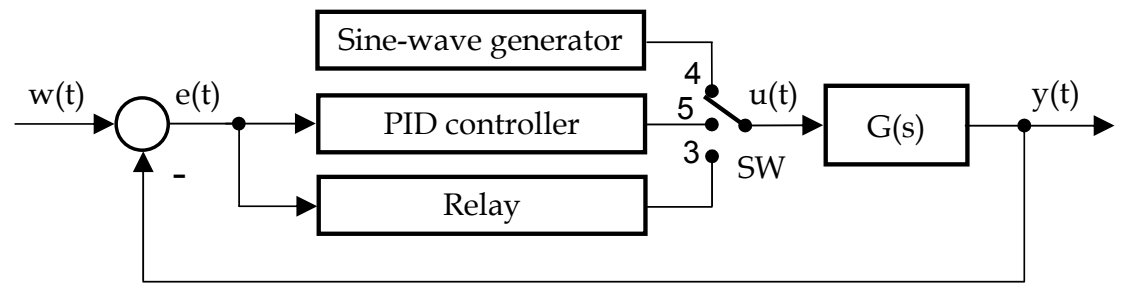

Fig. 7. Multipurpose loop for identification and control using the sine-wave method

\subsection{Plant identification by a sinusoidal excitation input}

By switching SW into "4", the loop in Fig. 7 opens; a stable plant with unknown model G(s) is excited by a persistent sinusoid $\mathrm{u}(\mathrm{t})=\mathrm{U}_{\mathrm{n}} \sin \left(\omega_{\mathrm{n}} \mathrm{t}\right)$ (Fig. 8a) where $\mathrm{U}_{\mathrm{n}}$ denotes the amplitude and $\omega_{n}$ excitation frequency. The plant output $y(t)=Y_{n} \sin \left(\omega_{n} t+\varphi\right)$ is also a persistent sinusoid with the same frequency $\omega_{n}$, amplitude $Y_{n}$ and phase shift $\varphi$ with respect to the input excitation sinusoid (Fig. 8b). From the stored records of $y(t)$ and $u(t)$ it is possible to read-off the amplitude $Y_{n}$ and phase shift $\varphi_{n}$ and thus to identify a particular point of the plant frequency response $G(j \omega)$ under excitation frequency $\omega_{n}$ with coordinates $G \equiv G\left(j \omega_{n}\right)$

$$
G\left(j \omega_{n}\right)=\left|G\left(j \omega_{n}\right)\right| e^{j \arg G\left(\omega_{n}\right)}=\frac{Y_{n}\left(\omega_{n}\right)}{U_{n}\left(\omega_{n}\right)} e^{j \arg G\left(\omega_{n}\right)}
$$

where $\varphi=\arg G\left(\omega_{n}\right)$. The point $G\left(j \omega_{n}\right)$ can be plotted in the complex plane (Fig. $8 \mathrm{c}$ ).
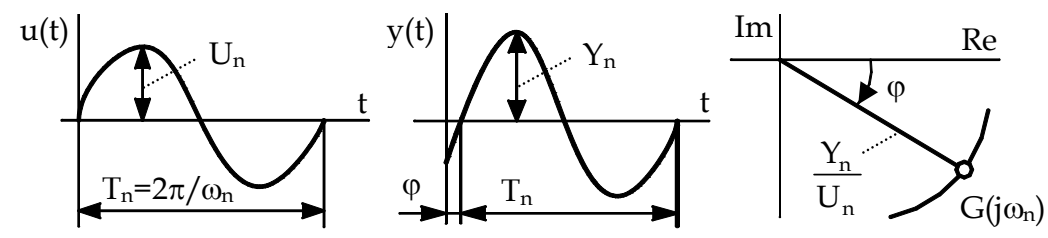

Fig. 8. Time responses of a) $u(t)$; b) $y(t)$, and c) location of $G\left(j \omega_{n}\right)$ in the complex plane 
The output sinusoid amplitude $Y_{n}$ can be affected by the amplitude $U_{n}$ of the excitation sinusoid generated by the sine wave generator; it is recommended to use $U_{n}=3 \div 7 \% u_{\max }$. Identified plant parameters are represented by the triple $\left\{\omega_{n}, Y_{n}\left(\omega_{n}\right) / U_{n}\left(\omega_{n}\right), \varphi\left(\omega_{n}\right)\right\}$. In the SW position " $4^{\prime \prime}$, identification is performed in the open-loop. Hence, this method is applicable only for stable plants. The excitation frequency $\omega_{\mathrm{n}}$ is to be adjusted prior to identification and taken from the empirical interval (29) (Bucz et al., 2010a, 2010b, 2011).

\subsection{Sine-wave method tuning rules}

In the control loop in Fig. 7, let us switch SW in ", 5 “ and put the PID controller into manual mode. The closed-loop characteristic equation $1+L(j \omega)=1+G(j \omega) G_{R}(j \omega)=0$ at the gain crossover frequency $\omega_{a}{ }^{*}$ can be broken down into the amplitude and phase conditions as follows

$$
\left|G\left(j \omega_{a}^{*}\right)\right|\left|G_{R}\left(j \omega_{a}^{*}\right)\right|=1 ; \quad \arg G\left(\omega_{a}^{*}\right)+\arg G_{R}\left(\omega_{a}^{*}\right)=-180^{\circ}+\phi_{M}
$$

where $\phi_{M}$ is the required phase margin, $\mathrm{L}\left(\mathrm{j} \omega_{\mathrm{n}}\right)$ is the open-loop transfer function. Denote $\Theta=\arg G_{R}\left(\omega_{a}^{*}\right)$. We are searching for $K, T_{i}$ and $T_{d}$ of the ideal PID controller (4a). Comparing frequency transfer functions of the PID controller in parallel and polar forms

$$
G_{R}(j \omega)=K+j K\left[T_{d} \omega-\frac{1}{T_{i} \omega}\right] ; \quad G_{R}(j \omega)=\left|G_{R}(j \omega)\right| e^{j \Theta}=\left|G_{R}(j \omega)\right| \cos \Theta+j\left|G_{R}(j \omega)\right| \sin \Theta
$$

coefficients of PID controller can be obtained from the complex equation

$$
K+j K\left[T_{d} \omega_{a}^{*}-\frac{1}{T_{i} \omega_{a}^{*}}\right]=\frac{\cos \Theta}{\left|G\left(j \omega_{a}^{*}\right)\right|}+j \frac{\sin \Theta}{\left|G\left(j \omega_{a}^{*}\right)\right|},
$$

at $\omega=\omega_{a}{ }^{*}$ using the substitution $\left|G_{R}\left(j \omega_{a}{ }^{*}\right)\right|=1 /\left|G\left(j \omega_{a}{ }^{*}\right)\right|$ resulting from the amplitude condition (20a). The complex equation (22) is solved as a set of two real equations

$$
K=\frac{\cos \Theta}{\left|G\left(j \omega_{a}^{*}\right)\right|} ; \quad K\left[T_{d} \omega_{a}^{*}-\frac{1}{T_{i} \omega_{a}^{*}}\right]=\frac{\sin \Theta}{\left|G\left(j \omega_{a}^{*}\right)\right|}
$$

where (23a) is a general rule for calculation of the controller gain $\mathrm{K}$. Using (23a) and the ratio of integration and derivative times $\beta=T_{i} / T_{d}$ in (23b), a quadratic equation in $T_{d}$ is obtained after some manipulations

$$
T_{d}^{2}\left(\omega_{a}^{*}\right)^{2}-T_{d} \omega_{a}^{*} \operatorname{tg} \Theta-\frac{1}{\beta}=0
$$

A positive solution of (24) yields the rule for calculating the derivative time $T_{d}$

$$
T_{d}=\frac{\operatorname{tg} \Theta}{2 \omega_{a}^{*}}+\frac{1}{\omega_{a}^{*}} \sqrt{\frac{\operatorname{tg}^{2} \Theta}{4}+\frac{1}{\beta}} ; \quad \Theta=-180^{\circ}+\phi_{M}-\arg G\left(\omega_{a}^{*}\right)
$$


where $\Theta=\arg G_{R}\left(\omega_{a}^{*}\right)$ is found from the phase condition (20b). Thus, using the PID controller with coefficients $\left\{K ; T_{i}=\beta T_{d} ; T_{d}\right\}$, the identified point $G\left(j \omega_{n}\right)$ of the plant frequency response with coordinates (19) can be moved on the unit circle $\mathrm{M}_{1}$ into the gain crossover $\mathrm{L}_{\mathrm{A}} \equiv \mathrm{L}\left(\mathrm{j} \omega_{\mathrm{a}}{ }^{*}\right)$; the required phase margin $\phi_{\mathrm{M}}$ is guaranteed if the following identity holds between the excitation and amplitude crossover frequencies $\omega_{n}$ and $\omega_{a}{ }^{*}$, respectively

$$
\omega_{a}^{*}=\omega_{n}
$$

Thus

$$
\left|G\left(j \omega_{a}^{*}\right)\right|=\left|G\left(j \omega_{n}\right)\right| ; \quad \arg G\left(\omega_{a}^{*}\right)=\arg G\left(\omega_{n}\right)=\varphi ; \quad \Theta=-180^{\circ}+\phi_{M}-\varphi
$$

and coordinates of the gain crossover $\mathrm{L}_{\mathrm{A}}$ are

$$
L_{A} \equiv L\left(j \omega_{a}^{*} \equiv j \omega_{n}\right)=\left[\left|L\left(j \omega_{n}\right)\right|, \arg L\left(\omega_{n}\right)\right]=\left[|1|,-180^{\circ}+\phi_{M}\right]
$$

Substituting (27a) and (27b) into (23a) and (23b), respectively, and (26) into (25a), tuning rules in Table 9 are obtained (Bucz et al., 2010a, 2010b, 2010c, 2011), (Bucz, 2011). Resulting PID controller coefficients guarantee required phase margin $\phi_{M}$ for $\beta=4$.

\begin{tabular}{|l|l|l|l|l|l|l|}
\hline No. & $\begin{array}{l}\text { Design } \\
\text { method, year }\end{array}$ & $\begin{array}{l}\text { Cont- } \\
\text { roller }\end{array}$ & $\mathrm{K}$ & $\mathrm{T}_{\mathrm{i}}$ & $\mathrm{T}_{\mathrm{d}}$ & $\begin{array}{l}\text { Range of } \Theta ; \\
\Theta=-180^{\circ}+\phi_{\mathrm{M}}-\varphi\end{array}$ \\
\hline 52. & $\begin{array}{l}\text { Sine-wave } \\
\text { method, 2010 }\end{array}$ & $\mathrm{PI}$ & $\frac{\cos \Theta}{\left|G\left(j \omega_{n}\right)\right|}$ & $\frac{-1}{\omega_{n} \operatorname{tg} \Theta}$ & - & $\left(-\frac{\pi}{2} ; 0\right)$ \\
\hline 53. & $\begin{array}{l}\text { Sine-wave } \\
\text { method, 2010 }\end{array}$ & $\mathrm{PD}$ & $\frac{\cos \Theta}{\left|G\left(j \omega_{n}\right)\right|}$ & - & $\frac{1}{\omega_{n}} \operatorname{tg} \Theta$ & $\left(0 ; \frac{\pi}{2}\right)$ \\
\hline 54. & $\begin{array}{l}\text { Sine-wave } \\
\text { method, 2010 }\end{array}$ & PID & $\frac{\cos \Theta}{\left|G\left(j \omega_{n}\right)\right|}$ & $\beta T_{d}$ & $\frac{\operatorname{tg} \Theta}{2 \omega_{n}}+\frac{1}{\omega_{n}} \sqrt{\frac{\operatorname{tg}^{2} \Theta}{4}+\frac{1}{\beta}}$ & $\left(-\frac{\pi}{2} ; \frac{\pi}{2}\right)$ \\
\hline
\end{tabular}

Table 9. PI, PD and PID controller tuning rules according to the sine-wave method

Note that PI controller tuning rules were derived for $T_{d}=0$, and PD tuning rules for $T_{i} \rightarrow \infty$ in (21a). The excitation frequency is taken from the interval (Bucz et al., 2011), (Bucz, 2011)

$$
\omega_{n} \in\left\langle 0,2 \omega_{c} ; 0,95 \omega_{c}\right\rangle
$$

obtained empirically by testing the sine-wave method on benchmark examples (Åström \& Hägglund, 2000). Shifting the point $G\left(j \omega_{n}\right)=\left|G\left(j \omega_{n}\right)\right| e e^{i}$ into the gain crossover $L_{A}\left(j \omega_{n}\right)$ on the unit circle $\mathrm{M}_{1}$ is depicted in Fig. 9a.

\subsection{Controller structure selection using the "triangle ruler" rule}

The argument $\Theta$ appearing in tuning rules in Tab. 9 indicates, what angle is to be contributed to the identified phase $\varphi$ by the controller at $\omega_{n}$ to obtain the resulting open-loop phase $\left(-180^{\circ}+\phi_{\mathrm{M}}\right)$ needed to provide the required phase margin $\phi_{\mathrm{M}}$. The working range of PID controller argument is the union of PI and PD controllers phase ranges symmetric with respect to $0^{\circ}$ 


$$
\Theta_{P I D} \in \Theta_{P I} \cup \Theta_{P D}=\left(-90^{\circ}, 0^{\circ}\right) \cup\left(0^{\circ},+90^{\circ}\right)=\left(-90^{\circ},+90^{\circ}\right)
$$

The working range (30) can be interpreted by means of an imaginary transparent triangular ruler turned as in Fig. 9b; its segments to the left and right of the axis of symmetry represent the PD and PI working ranges, respectively. Put this ruler on Fig. 9a, the middle of the hypotenuse on the complex plane origin and turn it so that its axis of symmetry merges with the ray $(0, G)$. Thus, the ruler determines in the complex plane the cross-hatched area representing the full working range of the PID controller argument. The controller type is chosen depending on the situation of the ray $\left(0, \mathrm{~L}_{\mathrm{A}}\right)$ forming the angle $\phi_{\mathrm{M}}$ with the negative real halfaxis: situation of the ray $\left(0, \mathrm{~L}_{\mathrm{A}}\right)$ in the left-hand-sector suggests PD controller, and in the right-hand sector the PI controller. The case when the phase margin $\phi_{M}$ is achievable using both PI or PID controller is shown in Fig. 9b (Bucz et al., 2010b, 2011), (Bucz, 2011).
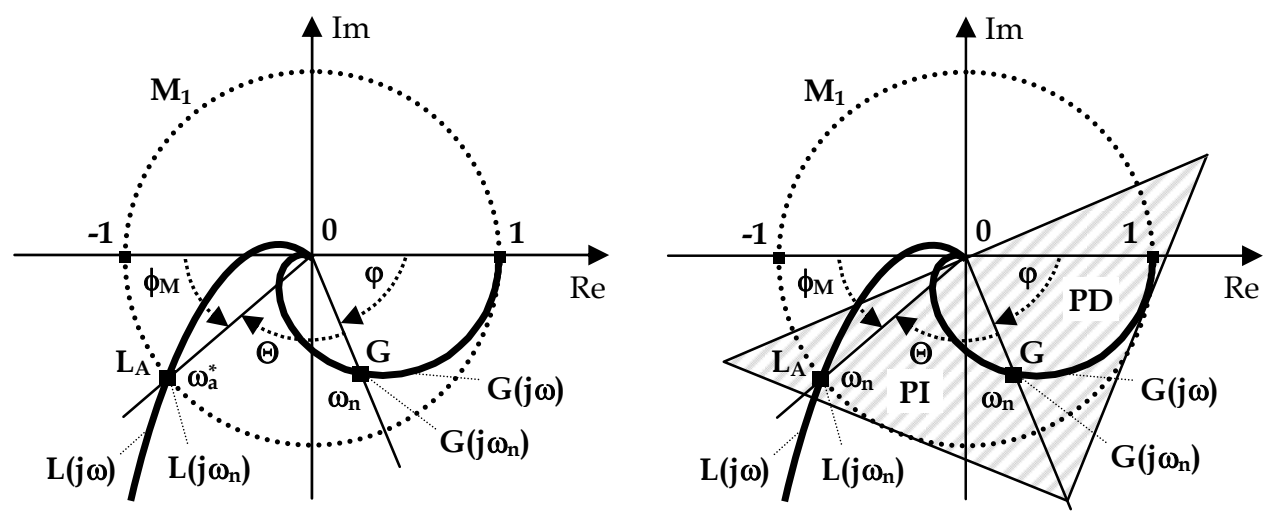

Fig. 9. a) Graphical interpretation of $\phi_{M}, \omega_{a}{ }^{*}$ and shifting $G$ into $L_{A}$ at $\omega_{a}{ }^{*}=\omega_{n} ;$ b) controller structure selection with respect to location of $\mathrm{G}$ and $\mathrm{L}_{\mathrm{A}}$ using the "triangle ruler" rule

\subsection{Evaluation of closed-loop performance under the sine-wave type PID controller}

This subsection answers the following question: how to transform required the maximum overshoot $\eta_{\max }$ and settling time $t_{\mathrm{s}}$ into the couple of frequency-domain parametres $\left(\omega_{n}, \phi_{\mathrm{M}}\right)$ needed for identification and PID controller coefficients tuning (Bucz, 2011)?

\subsubsection{Systems without integrator}

Looking for appropriate transformation $\mathfrak{R}:\left(\eta_{\max }, t_{\mathrm{s}}\right) \rightarrow\left(\omega_{\mathrm{n}}, \phi_{\mathrm{M}}\right)$ we have considered typical phase margins $\phi_{\mathrm{M}}$ given by the set

$$
\left\{\phi_{M j}\right\}=\left\{20^{\circ}, 30^{\circ}, 40^{\circ}, 50^{\circ}, 60^{\circ}, 70^{\circ}, 80^{\circ}, 90^{\circ}\right\}, j=1 \ldots 8
$$

split into 5 equal sections $\Delta \omega_{n}=0,15 \omega_{c}$; let us generate the set of excitation frequencies

$$
\left\{\omega_{n k}\right\}=\left\{0,2 \omega_{c} ; 0,35 \omega_{c} ; 0,5 \omega_{c} ; 0,65 \omega_{c} ; 0,8 \omega_{c} ; 0,95 \omega_{c}\right\}, \mathrm{k}=1 \ldots 6
$$

Elements of (32) divided by the plant critical frequency $\omega_{c}$ determine the set of so-called excitation levels 


$$
\left\{\sigma_{k}=\omega_{n k} / \omega_{c}\right\} \Rightarrow\left\{\sigma_{k}\right\}=\{0,2 ; 0,35 ; 0,5 ; 0,65 ; 0,8 ; 0,95\}, \mathrm{k}=1 \ldots 6
$$

Fig. 10 shows closed-loop step responses under PID controllers designed for the plant

$$
G_{1}(s)=\frac{1}{(s+1)(0,5 s+1)(0,25 s+1)(0,125 s+1)}
$$

for three different phase margins $\phi_{\mathrm{M}}=40^{\circ}, 60^{\circ}, 80^{\circ}$ each on three excitation levels $\sigma_{1}=\omega_{\mathrm{n} 1} / \omega_{\mathrm{c}}=0,2 ; \sigma_{3}=\omega_{\mathrm{n} 3} / \omega_{\mathrm{c}}=0,5$ and $\sigma_{5}=\omega_{\mathrm{n} 5} / \omega_{\mathrm{c}}=0,8$. Qualitative effect of $\omega_{\mathrm{nk}}$ and $\phi_{\mathrm{Mj}}$ on closed-loop step response is demonstrated.
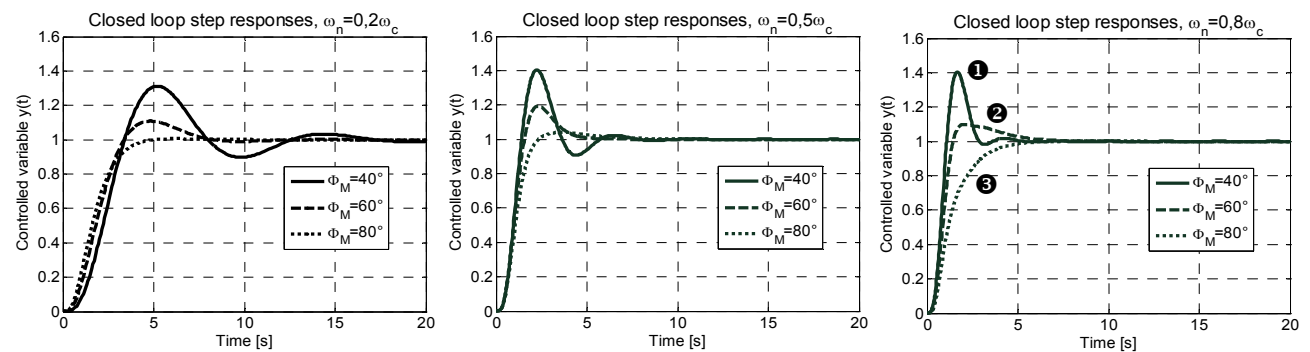

Fig. 10. Closed-loop step responses of $\mathrm{G}_{1}(\mathrm{~s})$ under PID controllers designed for various $\phi_{\mathrm{M}}$ and $\omega_{\mathrm{n}}$

Achieving $t_{\mathrm{s}}$ and $\eta_{\max }$ was tested by designing PID controller for a vast set of benchmark examples (Åström \& Hägglund, 2000) at excitation frequencies and phase margins expressed by a Cartesian product $\phi_{\mathrm{Mj}} \times \omega_{\mathrm{nk}}$ of (31) and (32) for $\mathrm{j}=1 \ldots 8, \mathrm{k}=1 \ldots 6$. Acquired dependencies $\eta_{\max }=f\left(\phi_{M}, \omega_{n}\right)$ and $t_{s}=\left(\phi_{M}, \omega_{n}\right)$ are plotted in Fig. 11 (Bucz et al., 2010b, 2011).
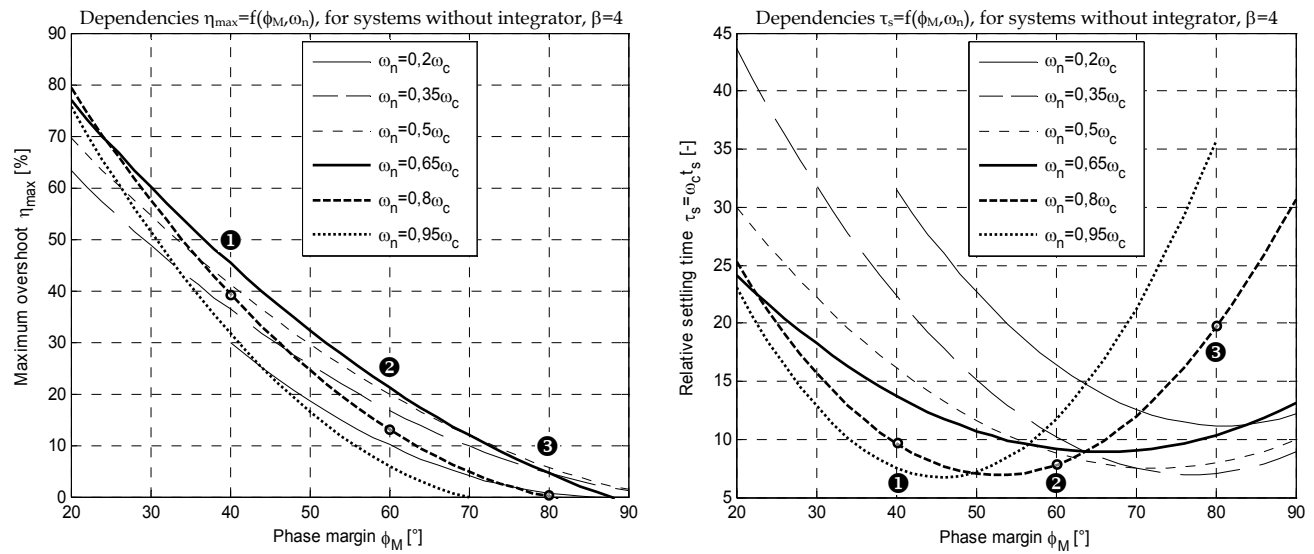

Fig. 11. Dependencies: a) $\left.\eta_{\max }=f\left(\phi_{M}, \omega_{n}\right) ; b\right) \tau_{s}=\omega_{c} t_{s}=f\left(\phi_{M}, \omega_{n}\right)$ for $\omega_{n k} \times \phi_{M j}, j=1 \ldots 8, k=1 \ldots 6$ (relative settling time $\tau_{s}$ is $t_{s}$ weighed by the critical frequency $\omega_{c}$ of the plant) 
Considering (26) resulting from the assumptions of the engineering method, the settling time can be expressed by the relation

$$
t_{s}=\frac{\gamma \pi}{\omega_{n}}
$$

similar to (17c) (Hudzovič, 1989), $\gamma$ is the curve factor of the step response. In (17c) valid for a $2^{\text {nd }}$ order closed-loop, $\gamma$ is from the interval $(1 ; 4)$ and depends on the relative damping (Hudzovič, 1989). In case of the proposed sine-wave method, $\gamma$ varies in a considerably broader interval $(0,5 ; 16)$ found empirically, and strongly depends on $\phi_{M}$, i.e. $\gamma=f\left(\phi_{M}\right)$ at the given excitation frequency $\omega_{\mathrm{n}}$. To examine closed-loop settling times of plants with various dynamics, it is advantageous to define the relative settling time (Bucz et al., 2011)

$$
\tau_{s}=t_{s} \omega_{c}
$$

Substituting $\omega_{\mathrm{n}}=\sigma \omega_{\mathrm{c}}$ into (35), the following relation for the relative settling time is obtained

$$
t_{s} \omega_{c}=\frac{\pi}{\sigma} \gamma \Rightarrow \tau_{s}=\frac{\pi}{\sigma} \gamma
$$

where $t_{s}$ is related to the critical frequency $\omega_{c}$. By substituting $\omega_{c}$ in (37) its left-hand side is constant for the given plant, independent of $\omega_{\mathrm{n}}$. Fig. 11b depicts (37b) empirically evaluated for different excitation frequencies $\omega_{\mathrm{nk}}$; it is evident that at every excitation level $\sigma_{\mathrm{k}}$ with increasing phase margin $\phi_{M}$ the relative settling time $\tau_{\mathrm{s}}$ first decreases and after achieving its minimum $\tau_{\mathrm{s}_{-} \min }$ it increases again. Empirical dependencies in Fig. 11 were approximated by quadratic regression curves and called B-parabolas. B-parabolas are a useful design tool to carry out the transformation $\mathfrak{R}:\left(\eta_{\max }, \mathrm{t}_{\mathrm{s}}\right) \rightarrow\left(\omega_{\mathrm{n}}, \phi_{\mathrm{M}}\right)$ that enables choosing appropriate values of phase margin and excitation frequencies $\phi_{M}$ and $\omega_{n}$, respectively, to provide performance specified in terms of maximum overshoot $\eta_{\max }$ and settling time $t_{s}$ (Bucz et al., 2011). Note that pairs of B-parabolas at the same level (Fig. 11a, Fig. 11b) are always to be used.

\section{Procedure 1. Specification of $\phi_{M}$ and $\omega_{n}$ from $\eta_{\max }$ and $t_{s}$ from B-parabolas prior to designing the controller}

1. Set the PID controller into manual mode. Find the plant critical frequency $\omega_{\mathrm{c}}$ using the multipurpose loop in Fig. 7 (SW in position ${ }^{3} 3^{\prime \prime}$ ).

2. From the required settling time $t_{s}$ calculate the relative settling time $\tau_{s}=\omega_{c} t_{s}$.

3. On the vertical axis of the plot in Fig. $11 \mathrm{~b}$ find the value of $\tau_{\mathrm{s}}$ calculated in Step 2.

4. Choose the excitation level $\sigma$ (e.g. $\left.\sigma_{5}=\omega_{n} / \omega_{c}=0,8\right)$.

5. For $\tau_{\mathrm{s}}$, find the corresponding phase margin $\phi_{\mathrm{M}}$ on the parabola $\tau_{\mathrm{s}}=\mathrm{f}\left(\phi_{\mathrm{M}}, \omega_{\mathrm{n}}\right)$ with the chosen excitation level found in Step 4.

6. Find $\phi_{\mathrm{M}}$ from Step 5 on the horizontal axis of the plot in Fig. 11a.

7. For $\phi_{\mathrm{M}}$, find the corresponding maximum overshoot $\eta_{\max }$ on the parabola $\eta_{\max }=\mathrm{f}\left(\phi_{\mathrm{M}}, \omega_{\mathrm{n}}\right)$ with the chosen excitation level found in Step 4.

8. If the found $\eta_{\max }$ is inappropriate, repeat Steps 4 to 7 for other parabolas $\tau_{s}=f\left(\phi_{M}, \omega_{n}\right)$ and $\eta_{\max }=\mathrm{f}\left(\phi_{\mathrm{M}}, \omega_{\mathrm{n}}\right)$ corresponding to other levels $\sigma_{\mathrm{k}}=\omega_{\mathrm{nk}} / \omega_{\mathrm{c}}$ (related with the choice $\sigma_{5}=\omega_{\mathrm{n} 5} / \omega_{\mathrm{c}}=0,8$ for $\left.\sigma_{\mathrm{k}}=\{0,2 ; 0,35 ; 0,50 ; 0,65 ; 0,95\}, \mathrm{k}=1 . .4,6\right)$. Repeat until both the required performance measures $\eta_{\max }$ and $t_{s}$ are satisfied. 
9. Calculate the excitation frequency $\omega_{\mathrm{n}}$ according to the relation $\omega_{\mathrm{n}}=\sigma \omega_{\mathrm{c}}$ using the critical frequency $\omega_{\mathrm{c}}$ (from Step 1) and the chosen excitation level $\sigma$ (from Step 4).

\section{Discussion}

When choosing $\phi_{\mathrm{M}}=40^{\circ}$ on the B-parabola corresponding to the excitation level $\sigma_{5}=\omega_{\mathrm{n} 5} / \omega_{\mathrm{c}}=0,8$ (further denoted as $\mathrm{B}_{0,8}$ parabola), maximum overshoot $\eta_{\max }=40 \%$ and relative settling time $\tau_{s} \approx 10$ are expected. Point ( corresponding to these parameters is located on the left (falling) portion of $\mathrm{B}_{0,8}$ yielding oscillatory step response (see response (1) in Fig. 10c). If the phase margin increases up to $\phi_{\mathrm{M}}=60^{\circ}$, the relative settling time decreases up to the point 2 on the right (rising) portion of the $\mathrm{B}_{0,8}$ parabola; the corresponding step response 2 in Fig. 10c is weakly-aperiodic. For the phase margin $\phi_{\mathrm{M}}=80^{\circ}$ the $\mathrm{B}_{0,8}$ parabola indicates a zero maximum overshoot, the relative settling time $\tau_{\mathrm{s}}=20$ corresponds to the position 3 on the $B_{0,8}$ parabola with aperiodic step response 3 (Fig. 10c). If the maximum overshoot $\eta_{\max }=20 \%$ is acceptable then $\phi_{\mathrm{M}}=53^{\circ}$ yields the least possible relative settling time $\tau_{\mathrm{s}}=6,5$ on the given level $\sigma_{5}=0,8$ ("at the bottom" of $\left.\mathrm{B}_{0,8}\right)$ (Bucz et al., 2011), (Bucz, 2011).

\section{Procedure 2. PID controller design using the sine-wave engineering method}

1. From the required values $\left(\eta_{\max }, t_{\mathrm{s}}\right)$ specify the couple $\left(\omega_{n} ; \phi_{M}\right)$ using Procedure 1.

2. Identify the plant using the sinusoidal excitation signal with frequency $\omega_{\mathrm{n}}$ specified in Procedure 1. The switch SW is in position " 4 ".

3. Specify $\varphi=\arg G\left(\omega_{n}\right)$, and $\left|G\left(j \omega_{n}\right)\right|$. Calculate the controller argument $\Theta$ by substituting $\varphi$ and $\phi_{\mathrm{M}}$ into (27c); if $\Theta$ is within the range shown in the last column of Tab. 9, go to Step 4 , if not, change $\left(\omega_{\mathrm{n}} ; \phi_{\mathrm{M}}\right)$ and repeat Steps 1-3.

4. Substitute the identified values $\varphi=\arg G\left(\omega_{n}\right),\left|G\left(j \omega_{n}\right)\right|$ and specified $\phi_{M}$ into the tuning rules in Tab. 9 to calculate PID controller parameters.

5. Adjust the resulting PID controller values, switch into automatic mode and complete the controller by switching SW into position " 5 .

\section{Example 1}

Using the sine-wave method, ideal PID controller (4a) is to be designed for the operating amplifier modelled by the transfer function $\mathrm{G}_{\mathrm{A}}(\mathrm{s})$

$$
G_{A}(s)=\frac{1}{\left(T_{A} s+1\right)^{3}}=\frac{1}{(0,01 s+1)^{3}}
$$

The controller has to be designed for two values of the maximum overshoot of the closedloop step response $\eta_{\max 1}=30 \%$ (Design No. 1) and $\eta_{\max 2}=5 \%$ (Design No. 2) and maximum relative settling time $\tau_{\mathrm{s}}=12$ in both cases.

\section{Solution}

1. Critical frequency of the plant identified by the Rotach test is $\omega_{\mathrm{c}}=173,216[\mathrm{rad} / \mathrm{s}]$ (the process is "fast"). The prescribed settling time is $t_{s}=\tau_{s} / \omega_{c}=12 / 173,216[\mathrm{~s}]=69,3[\mathrm{~ms}]$.

2. For the Design No. $1 \quad\left(\eta_{\max 1} ; \tau_{\mathrm{s}}\right)=(30 \% ; 12)$, a suitable choice is $\left(\phi_{\mathrm{M} 1} ; \omega_{\mathrm{n} 1}\right)=\left(50^{\circ} ; 0,5 \omega_{\mathrm{c}}\right)$ resulting from the $\mathrm{B}_{0,5}$ parabola in Fig. 11. The performance in Design No. 2 $\left(\eta_{\max 2} ; \tau_{\mathrm{s}}\right)=(5 \% ; 12)$ can be achieved for $\left(\phi_{\mathrm{M} 2} ; \omega_{\mathrm{n} 2}\right)=\left(70^{\circ} ; 0,8 \omega_{\mathrm{c}}\right)$ chosen from the $\mathrm{B}_{0,8}$ parabola in Fig. 11.

3. Identified points for the Designs No. 1 and No. 2 are $G_{A}\left(j 0,5 \omega_{c}\right)=0,43 e^{-j 120^{\circ}}$ and $G_{A}\left(j 0,8 \omega_{c}\right)=0,19 e^{-j 165^{\circ}}$, respectively. According to Fig. $12 a$, both points are located in the 
Quadrant II of the complex plane, on the Nyquist plot $\mathrm{G}_{\mathrm{A}}(\mathrm{j} \omega)$ (solid line) which verifies the identification.

4. Using the PID controller designed for $\left(\phi_{\mathrm{M} 1} ; \omega_{\mathrm{n} 1}\right)=\left(50^{\circ} ; 0,5 \omega_{\mathrm{c}}\right)$, the point $\mathrm{G}_{\mathrm{A}}\left(j 0,5 \omega_{\mathrm{c}}\right)$ is moved into the gain crossover $L_{A 1}\left(j 0,5 \omega_{c}\right)=1 e^{-j 130^{\circ}}$ on the unit circle $M_{1}$, which verifies achieving the phase margin $\phi_{\mathrm{M} 1}=180^{\circ}-130^{\circ}=50^{\circ}$ (dashed line in Fig. 12a). The point $G_{A}\left(j 0,8 \omega_{c}\right)$ has been moved into $\mathrm{L}_{\mathrm{A} 2}\left(\mathrm{j} 0,8 \omega_{\mathrm{c}}\right)=1 \mathrm{e}^{-\mathrm{j} 110^{\circ}}$ by the PID controller designed for $\left(\phi_{\mathrm{M} 2} ; \omega_{\mathrm{n} 2}\right)=\left(80^{\circ} ; 0,8 \omega_{\mathrm{c}}\right)$ yielding the phase margin $\phi_{\mathrm{M} 2}=180^{\circ}-110^{\circ}=70^{\circ}$ (dotted line in Fig. 12a).

5. Achieved performance according to the closed-loop step response in Fig. $12 \mathrm{~b}$ (dashed line) is $\eta_{\max 1}{ }^{*}=29,7 \%, \mathrm{t}_{\mathrm{s} 1}{ }^{*}=58,4[\mathrm{~ms}]$. Performance in terms of $\eta_{\max 2}{ }^{*}=4,89 \%, \mathrm{t}_{\mathrm{s} 2}{ }^{*}=60,5[\mathrm{~ms}]$ identified from the closed-loop step response in Fig. 12b (dotted line) fulfils the performance requirements.
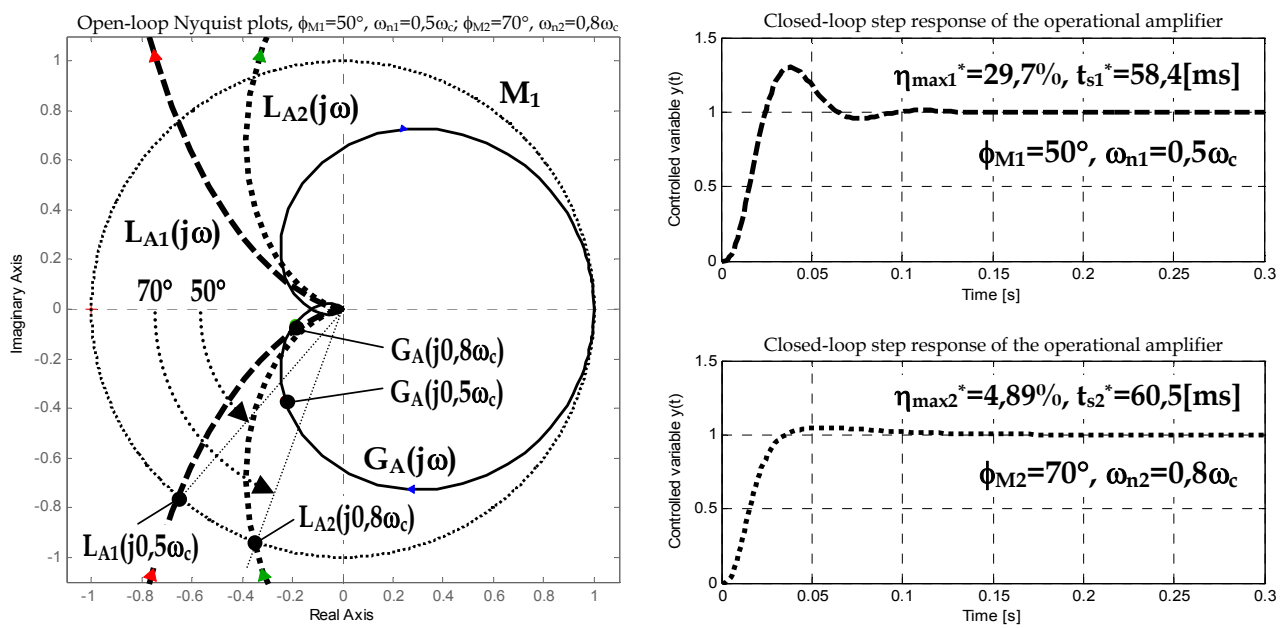

Fig. 12. a) Open-loop Nyquist plots; b) closed-loop step responses of the operational amplifier, required performance $\eta_{\max 1}=30 \%, \eta_{\max 2}=5 \%$ and $\tau_{s}=12$

\subsubsection{Systems with time delay}

The sine-wave method is applicable also for plants with time delay considered as difficultto-control systems. It is a well-known fact, that the time delay D turns the phase at each frequency $\omega_{n} \in\langle 0, \infty)$ by $\omega_{n} D$ with respect to the delay-free system. For time delayed plants, phase condition of the sine-wave method $(20 \mathrm{~b})$ is extended by additional phase $\varphi_{D}=-\omega_{n} D$

$$
\left(\varphi^{\prime}+\varphi_{D}\right)+\Theta=-180^{\circ}+\phi_{M}
$$

where $\varphi^{\prime}$ is the phase of the delay-free system and

$$
\varphi=\varphi^{\prime}+\varphi_{D}
$$

is the identified phase of the plant including the time delay. The added phase $\varphi_{D}=-\omega_{n} D$ can be associated with the required phase margin $\phi_{M}$ 


$$
\varphi^{\prime}+\Theta=-180^{\circ}+\left(\phi_{M}+\omega_{n} D\right)
$$

The only modification in using the PID tuning rules in Tab. 9 is that increased required phase margin is to be specified (Bucz, 2011)

$$
\phi_{M}=\phi_{M}+\omega_{n} D
$$

and the controller working angle $\Theta$ is computed using the relation

$$
\Theta=-180^{\circ}-\varphi^{\prime}+\left(\phi_{M}+\omega_{n} D\right)
$$

The phase delay $\omega_{n} \mathrm{D}$ increases with increasing frequency of the sinusoidal signal $\omega_{\mathrm{n}}$.

To lessen the impact of time delay on closed-loop dynamics, it is recommended to use the smallest possible added phase $\varphi_{D}=-\omega_{n} D$.

\section{Discussion}

Time delay $\mathrm{D}$ can easily be specified during critical frequency identification as the time $D=T_{y}-T_{u}$, that elapses since the start of the test at time $T_{u}$ until time $T_{y}$, when the system output starts responding to the excitation signal $u(t)$. A small added phase $\varphi_{D}=-\omega_{n} D$ due to time delay can be secured by choosing the smallest possible $\omega_{n}$ attenuating effect of D in (43) and subsequently in the PID controller design.

Therefore, when designing PID controller for time delayed systems according to Procedure 1 , in Step 4 it is recommended to choose the lowest possible excitation level on the performance B-parabolas (most frequently $\omega_{\mathrm{n}} / \omega_{\mathrm{c}}=0,2$ resp. 0,35 ) and corresponding couples of B-parabolas in Fig. 11. Procedure 2 is used for plant identification and PID controller design. $\phi_{M}$ is specified from the given couple $\left(\eta_{\max } ; t_{\mathrm{s}}\right)$ using the chosen couple of Bparabolas, however its increased value $\phi_{\mathrm{M}^{\prime}}$ given by (42) is to be supplied in the design algorithm thus minimizing effect of the time delay on closed-loop dynamics.

\section{Example 2}

Using the sine-wave method, ideal PID controllers (4a) are to be designed for the distillation column modelled by the transfer function $\mathrm{G}_{\mathrm{B}}(\mathrm{s})$

$$
G_{B}(s)=\frac{K_{B} e^{-D_{B} s}}{T_{B} s+1}=\frac{1,11 e^{-6,5 s}}{3,25 s+1}
$$

Control objectives are the same as in Example 1.

\section{Solution}

1. Critical frequency of the plant is $\omega_{\mathrm{c}}=0,3521[\mathrm{rad} / \mathrm{s}]$. Based on comparison of critical frequencies, $G_{B}(s)$ is 500 -times slower than $G_{A}(s)$. Required settling time is $t_{s}=\tau_{s} / \omega_{c}=$ $=12 / 0,3521[\mathrm{~s}]=34,08[\mathrm{~s}]$.

2. Because $D_{B} / T_{B}=2>1$, the plant is a so-called "dead-time dominant system". Due to a large the time delay, it is necessary to choose the lowest possible excitation frequency $\omega_{n}$ to minimize the added phase $\omega_{n} D_{B}$ in (43). Hence, for the required performance $\left(\eta_{\max 2} ; \tau_{\mathrm{s}}\right)=(5 \% ; 12)$ (Design No. 2) we choose the $\mathrm{B}_{0,2}$ parabolas in Fig. 11 at the lowest possible level $\omega_{\mathrm{n}} / \omega_{\mathrm{c}}=0,2$ to find $\left(\phi_{\mathrm{M} 2} ; \omega_{\mathrm{n} 2}\right)=\left(70^{\circ} ; 0,2 \omega_{\mathrm{c}}\right)$. The added phase is 
$\omega_{\mathrm{n} 2} \mathrm{D}_{\mathrm{B}}\left(180^{\circ} / \pi\right)=0,2 \omega_{\mathrm{C}} \mathrm{D}_{\mathrm{B}}\left(180^{\circ} / \pi\right)=0,2.0,3521.6,5.180^{\circ} / \pi=26,2^{\circ}$, hence the phase supplied to the PID design algorithm is $\phi^{\prime}{ }_{\mathrm{M} 2}=\phi_{\mathrm{M} 2}+\omega_{\mathrm{n} 2} \mathrm{D}_{\mathrm{B}}\left(180^{\circ} / \pi\right)=70^{\circ}+26,2^{\circ}=96,2^{\circ}$ (instead of $\phi_{\mathrm{M} 2}=70^{\circ}$ for a delay-free system). The required performance $\left(\eta_{\max 1} ; \tau_{\mathrm{s}}\right)=(30 \% ; 12)$ (Design No. 1) can be achieved by choosing $\left(\phi_{\mathrm{M} 1} ; \omega_{\mathrm{n} 1}\right)=\left(55^{\circ} ; 0,35 \omega_{\mathrm{c}}\right)$ from the $\mathrm{B}_{0,35}$ parabolas in Fig. 11 (i.e. $\omega_{\mathrm{n}} / \omega_{\mathrm{c}}=0,35$ ). The phase margin $\phi_{\mathrm{M} 1}^{\prime}=55^{\circ}+45,9^{\circ}$ supplied into the design algorithm was increased by $\omega_{\mathrm{n} 1} \mathrm{D}_{\mathrm{B}}\left(180^{\circ} / \pi\right)=0,35 \omega_{\mathrm{C}} \mathrm{D}_{\mathrm{B}}\left(180^{\circ} / \pi\right)=0,35 \cdot 0,3521 \cdot 6,5 \cdot 180^{\circ} / \pi=$ $=45,9^{\circ}$ compared with $\phi_{\mathrm{M} 1}=55^{\circ}$ in case of delay-free system.

3. Identified points $G_{B}\left(j 0,35 \omega_{c}\right)=1,03 e^{-j 23^{\circ}}$ and $G_{B}\left(j 0,2 \omega_{c}\right)=1,09 e^{-j 13^{\circ}}$ in Fig. 13a are located in the Quadrant I of the complex plane at the beginning of the frequency response $G_{B}(j \omega)$ (solid line). The point $\mathrm{G}_{\mathrm{B}}\left(\mathrm{j} 0,2 \omega_{\mathrm{c}}\right)$ (Design No. 2) was shifted by the PID controller to the open-loop gain crossover $\mathrm{L}_{B 2}\left(j 0,2 \omega_{c}\right)=1 \mathrm{e}^{-j 110^{\circ}}$ (dotted line in Fig. 13a). Note that $\mathrm{L}_{B 2}$ has the same location in the complex plane as $\mathrm{L}_{\mathrm{A} 2}$ in Fig. 12a, however at a considerably lower frequency $\omega_{\mathrm{n} 2 \mathrm{~B}}=0,2 \cdot 0,3521=0,07[\mathrm{rad} / \mathrm{s}]$ compared to $\omega_{\mathrm{n} 2 \mathrm{~A}}=0,8 \cdot 173,216=$ $=138,6[\mathrm{rad} / \mathrm{s}]\left(\mathrm{t}_{\mathrm{s} 2 \_} \mathrm{B}^{*}=28,69[\mathrm{~s}]\right.$ is almost 500 times larger than $\mathrm{t}_{\mathrm{s} 2 \_} \mathrm{A}^{*}=0,0584[\mathrm{~s}]$ which demonstrates the key role of the excitation frequency $\omega_{n}$ in achieving required closedloop dynamics). The identified point $\mathrm{G}_{\mathrm{B}}\left(\mathrm{j0} 0,35 \omega_{\mathrm{c}}\right)$ (Design No. 1) was moved into the gain crossover $\mathrm{L}_{\mathrm{B} 1}\left(\mathrm{j} 0,35 \omega_{\mathrm{c}}\right)=1 \mathrm{e}^{-\mathrm{j} 125^{\circ}}$ (dashed line in Fig. 13a).

4. Achieved performances $\left(\eta_{\max 1}{ }^{*}=18,6 \%, t_{s 1}{ }^{*}=24,78[\mathrm{~s}]\right.$, dashed line $), \quad\left(\eta_{\max 2}{ }^{*}=0,15 \%\right.$, $\mathrm{t}_{\mathrm{s} 2}{ }^{*}=28,69$ [s], dotted line) in terms of closed-loop step responses in Fig. 13b comply with the required performance specification.
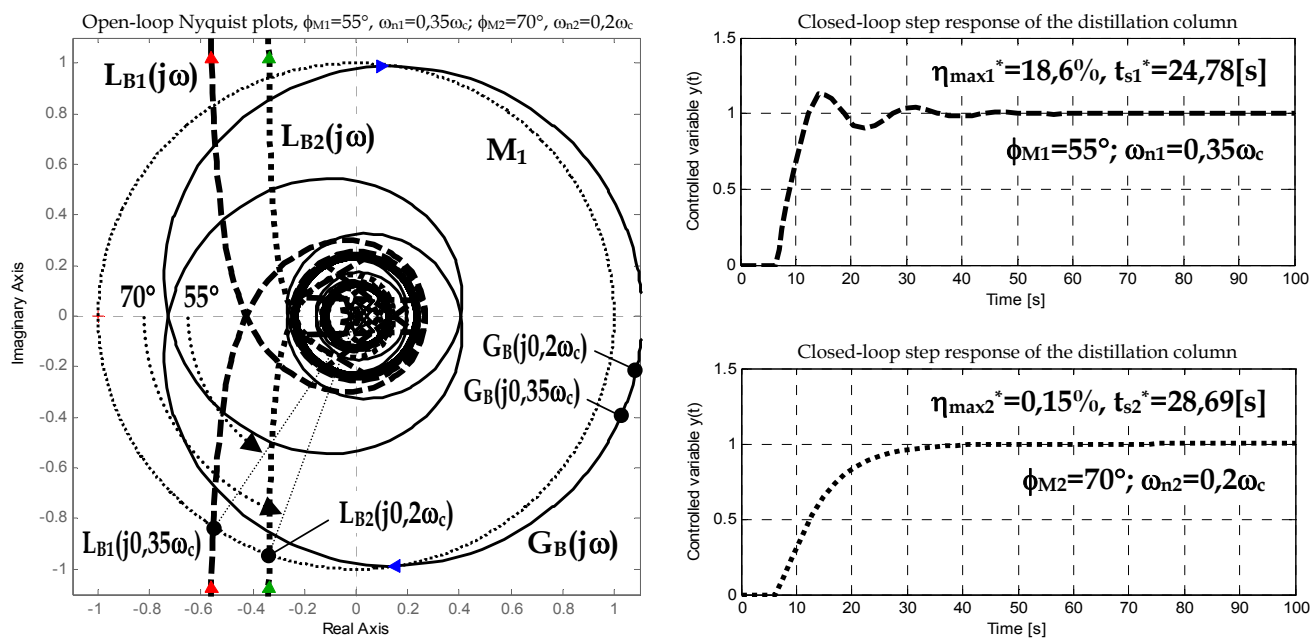

Fig. 13. a) Open-loop Nyquist plots; b) closed-loop step responses of the distillation column, required performance $\eta_{\max 1}=30 \%, \eta_{\max 2}=5 \%$ and $\tau_{\mathrm{s}}=12$

\subsubsection{Systems with $1^{\text {st }}$ order integrator}

By testing the sine-wave method on benchmark systems with $1^{\text {st }}$ order integrator, the B-parabolas in Fig. 14 - 16 were obtained (for Cartesian product $\phi_{\mathrm{Mj}} \times \omega_{\mathrm{nk}}$ of sets (31) and (32), $j=1 . .8, k=1 \ldots 6$ and three various ratios $T_{i} / T_{d}: \beta=4,8$ and 12$)$. 


\section{Discussion}

Inspection of Fig. 14a, 15a and 16a reveals, that increasing $\beta$ results in decreasing of the maximum overshoot $\eta_{\max }$, narrowing of the B-parabolas of relative settling times $\tau_{s}=f\left(\phi_{M}, \omega_{n}\right)$ for each identification level $\omega_{\mathrm{n}} / \omega_{\mathrm{c}}$, and consequently settling time increasing. Consider e.g. the $B_{0,95}$ parabolas in Fig. $14 b$, Fig. $15 \mathrm{~b}$ and Fig. $16 \mathrm{~b}$ : if $\phi_{\mathrm{M}}=70^{\circ}$ and $\beta=4$, relative settling time is $\tau_{s}=30$, for $\beta=8$ it grows to $\tau_{s}=40$, and for $\beta=12$ even to $\tau_{s}=45$. If a $10 \%$ maximum overshoot is acceptable, then the standard interaction PID controller can be used with no need to use a setpoint filter; however a larger settling time is to be expected.

Procedure 1 is used to specify the performance in terms of $\left(\phi_{M}, \omega_{n}\right)$ from $\left(\eta_{\max }, t_{s}\right)$ using pertinent B-parabolas in Fig. 14 - 16. Procedure 2 is used for plant identification and PID controller design.

\section{Example 3}

Using the sine-wave method, design ideal PID controller for the flow valve modelled by the transfer function $\mathrm{G}_{\mathrm{C}}(\mathrm{s})$ (system with integrator and time delay)

$$
G_{C}(s)=\frac{K_{C} e^{-D_{C} s}}{s\left(T_{C} s+1\right)}=\frac{1,3 e^{-2,1 s}}{s(7,51 s+1)}
$$

Control objective is to provide the maximum overshoots of the closed-loop step response $\eta_{\max 1}=30 \%, \eta_{\max 2}=20 \%$ and a maximum relative settling time $\tau_{\mathrm{s}}=20$.

\section{Solution}

1. Critical frequency of the plant identified by the Rotach test is $\omega_{\mathrm{c}}=0,2407[\mathrm{rad} / \mathrm{s}]$. Then, the required settling time is $t_{s}=\tau_{s} / \omega_{c}=20 / 0,2407[s]=83,09[s]$.

2. For $G_{C}(s)$ the time delay/time constant ratio is $D_{C} / T_{C}=2,1 / 7,51=0,28<1$, hence, the influence of the time constant prevails - $\mathrm{G}_{\mathrm{C}}(\mathrm{s})$ is a so-called "lag-dominant system" with integrator, therefore B-parabolas are to be chosen carefully. From one side, due to time delay it would be desirable to choose B-parabolas from Fig. 14, Fig. 15 or Fig. 16 with the lowest identification level $\omega_{n} / \omega_{c}=0,2$. However, the minima of $B_{0,2}$ parabolas in Fig. 14b (for $\beta=4$ ), Fig. 15b (for $\beta=8$ ) and Fig. 16b (for $\beta=12$ ) indicate the smallest achievable relative settling time $\tau_{s}=36,5$ (for $\beta=4$ ), $\tau_{s}=33$ (for $\beta=8$ ) and $\tau_{s}=34$ (for $\beta=12$ ), which do not satisfy the required value $\tau_{\mathrm{s}}=20$.

3. Identified points $G_{C}\left(j 0,35 \omega_{c}\right)=12,7 \mathrm{e}^{-j 122^{\circ}}$ and $G_{C}\left(j 0,5 \omega_{c}\right)=8,10 e^{-j 129^{\circ}}$ are located on the plant frequency response $G_{C}(j \omega)$ (solid line) in Fig. 17a, verifying correctness of the sine-wave type identification.

4. The first performance specification $\left(\eta_{\max 1} ; \tau_{\mathrm{s}}\right)=(30 \% ; 20)$ can be provided using the $\mathrm{B}_{0,35}$ parabolas for $\beta=12$ (Fig. 16b) at the level $\omega_{\mathrm{n}} / \omega_{\mathrm{c}}=0,35$ and for parameters $\left(\phi_{\mathrm{M} 1} ; \omega_{\mathrm{n} 1}\right)=$ $=\left(53^{\circ} ; 0,35 \omega_{\mathrm{c}}\right)$ (Design No. 1), supplying the augmented open-loop phase margin $\phi_{\mathrm{M} 1}^{\prime}=\phi_{\mathrm{M} 1}+\left(180^{\circ} / \pi\right) \omega_{\mathrm{n} 1} \mathrm{D}_{\mathrm{C}}=53^{\circ}+10,1^{\circ}=63,1^{\circ}$ into the controller design algorithm. The second performance specification $\left(\eta_{\max 2} ; \tau_{s}\right)=(20 \%, 20)$ is achievable using the $B_{0,5}$ parabolas in Fig. 16 for $\beta=12$ and $\omega_{\mathrm{n}} / \omega_{\mathrm{c}}=0,5$ and parametres $\left(\phi_{\mathrm{M} 2} ; \omega_{\mathrm{n} 2}\right)=\left(62^{\circ} ; 0,5 \omega_{\mathrm{c}}\right)$ (Design No. 2). To reject the influence of $D_{\mathrm{C}}$, instead of $\phi_{\mathrm{M} 2}=62^{\circ}$ the augmented openloop phase margin $\phi_{\mathrm{M} 2}^{\prime}=\phi_{\mathrm{M} 2}+\left(180^{\circ} / \pi\right) \omega_{\mathrm{n} 2} \mathrm{D}_{\mathrm{C}}=62^{\circ}+14,5^{\circ}=76,5^{\circ}$ was supplied into the PID controller design algorithm. 

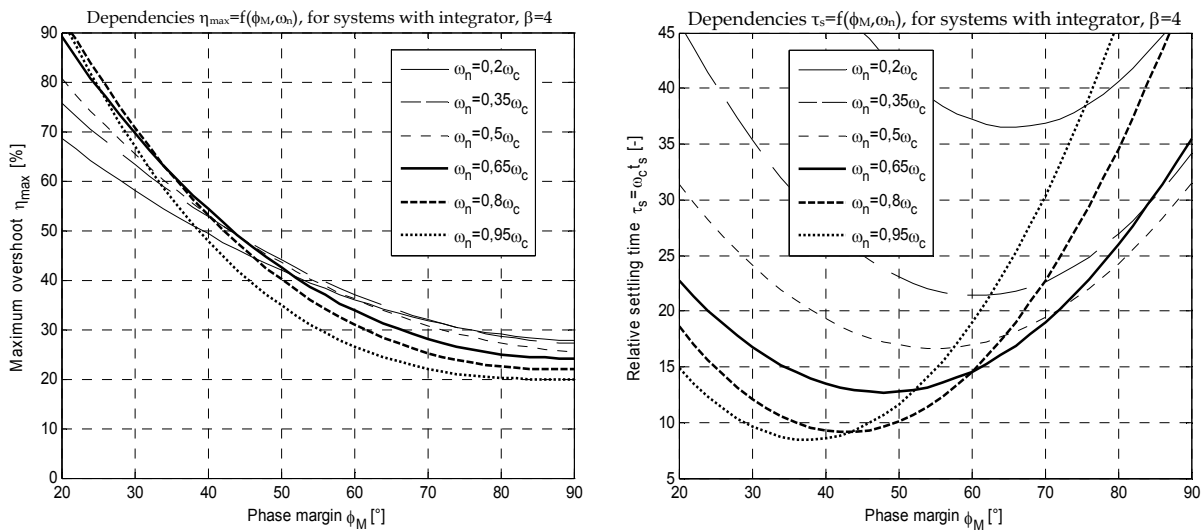

Fig. 14. B-parabolas: a) $\left.\eta_{\max }=f\left(\phi_{M}, \omega_{n}\right) ; b\right) \tau_{s}=\omega_{c} t_{s}=f\left(\phi_{M}, \omega_{n}\right)$ for systems with integrator, $\beta=4$
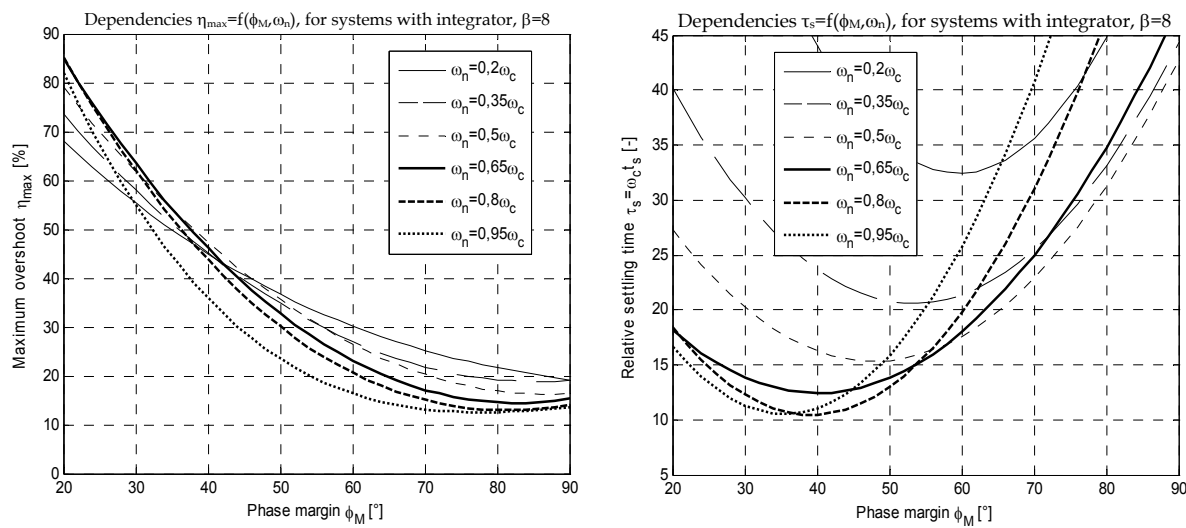

Fig. 15. B-parabolas: a) $\left.\eta_{\max }=f\left(\phi_{M}, \omega_{n}\right) ; b\right) \tau_{s}=\omega_{c} t_{s}=f\left(\phi_{M}, \omega_{n}\right)$ for systems with integrator, $\beta=8$
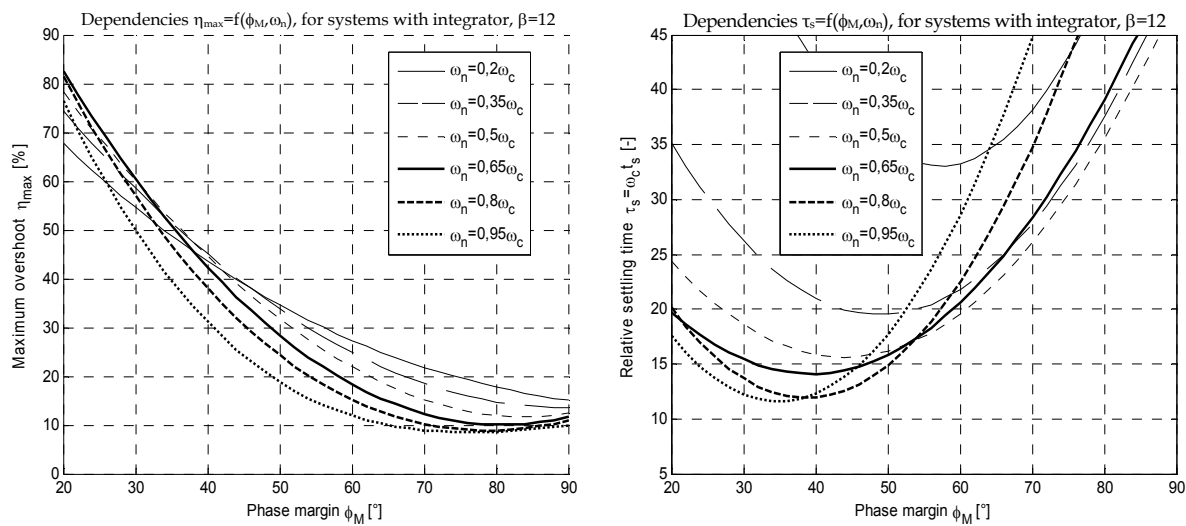

Fig. 16. B-parabolas: a) $\left.\eta_{\max }=f\left(\phi_{M}, \omega_{n}\right) ; b\right) \tau_{s}=\omega_{c} t_{s}=f\left(\phi_{M}, \omega_{n}\right)$ for systems with integrator, $\beta=12$ 

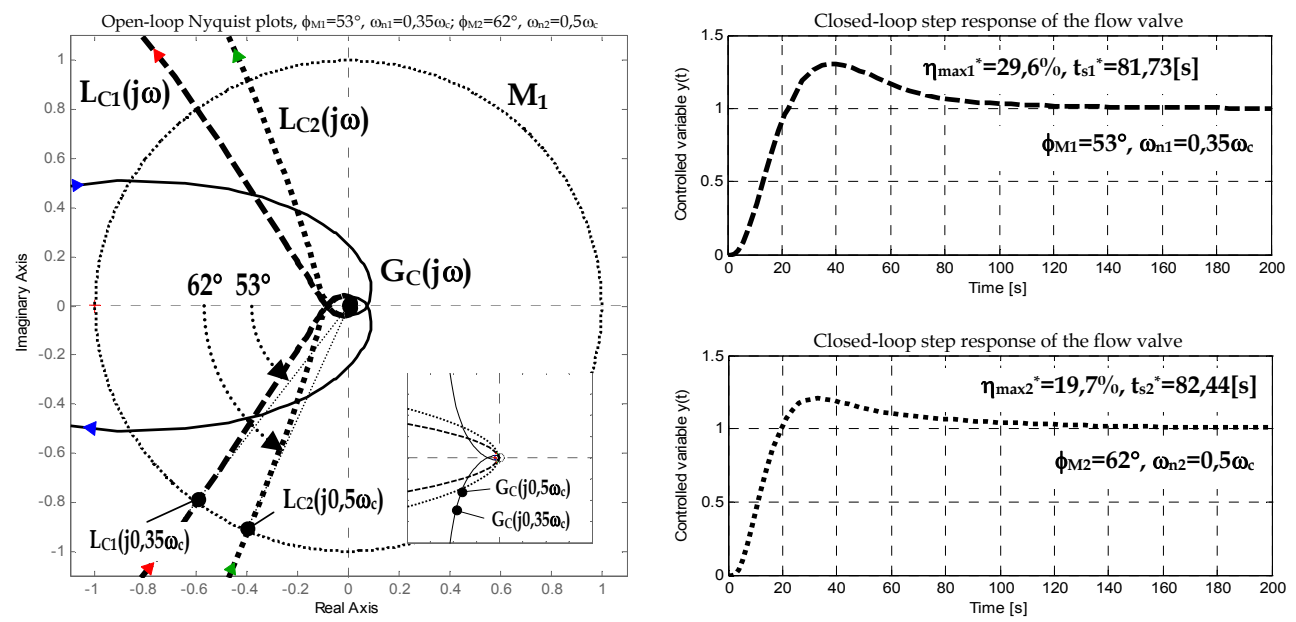

Fig. 17. a) Open-loop Nyquist plots; b) closed-loop step responses of the flow valve, required performance $\eta_{\max 1}=30 \%, \eta_{\max 2}=20 \%$ and $\tau_{s}=20$

5. Using the PID controller, the first identified point $\mathrm{G}_{\mathrm{C}}\left(\mathrm{j} 0,35 \omega_{\mathrm{c}}\right)$ (Design No. 1) was moved into the gain crossover $\mathrm{L}_{\mathrm{C} 1}\left(\mathrm{j} 0,35 \omega_{\mathrm{c}}\right)=1 \mathrm{e}^{-\mathrm{j} 127^{\circ}}$ located on the unit circle $\mathrm{M}_{1}$; this verifies achieving the phase margin $\phi_{\mathrm{M} 1}=180^{\circ}-127^{\circ}=53^{\circ}$ (dashed line in Fig. 17a). Achieved performance in terms of the closed-loop step response in Fig. $17 \mathrm{~b}$ is $\eta_{\max 1}{ }^{*}=29,6 \%$, $\mathrm{t}_{\mathrm{s} 1}{ }^{*}=81,73[\mathrm{~s}]$ (dashed line). The second identified point $\mathrm{G}_{\mathrm{C}}\left(\mathrm{j0}, 5 \omega_{\mathrm{c}}\right)$ (Design No. 2) was moved into $L_{\mathrm{C} 2}\left(j 0,5 \omega_{\mathrm{c}}\right)=1 \mathrm{e}^{-j 118^{\circ}}$ achieving the phase margin $\phi_{\mathrm{M} 2}=180^{\circ}-118^{\circ}=62^{\circ}$ (dotted line in Fig. 17a). Achieved performance in terms of the closed-loop step response parameters $\eta_{\max 2}{ }^{*}=19,7 \%, \mathrm{t}_{\mathrm{s} 2}{ }^{*}=82,44[\mathrm{~s}]$ (dotted line in Fig. 17b) meets the required specification. Frequency characteristics $\mathrm{L}_{\mathrm{C} 1}(\mathrm{j} \omega), \mathrm{L}_{\mathrm{C} 2}(\mathrm{j} \omega)$ begin near the negative real halfaxis of the complex plane, because both open-loops contain a $2^{\text {nd }}$ order integrator.

\section{Discussion}

All data necessary to design two PID controllers of all three plants $G_{A}(s), G_{B}(s)$ and $G_{C}(s)$ along with specified and achieved performance measure values are summarized in Tab. 10 where $\eta_{\max }$ and $t_{s}$ in the last two columns marked with " ${ }^{\star} “$ indicate closed-loop performance complying with the required one.

\begin{tabular}{|c|c|c|c|c|c|c|c|c|c|c|}
\hline Model & $\eta_{\text {max }} \tau_{\mathrm{s}}$ & $\omega_{\mathrm{C}}[\mathrm{rad} / \mathrm{s}]$ & $\mathrm{t}_{\mathrm{s}}[\mathrm{s}]$ & B-par. & $\phi_{\mathrm{M}}$ & $\omega_{\mathrm{n}} / \omega_{\mathrm{c}}$ & $\mathrm{G}\left(\mathrm{j} \omega_{\mathrm{n}}\right)$ & $\mathrm{G}_{\mathrm{R}}\left(\mathrm{j} \omega_{\mathrm{n}}\right)$ & $\eta_{\max }{ }^{*}$ & $\mathrm{t}_{\mathrm{s}}{ }^{*}[\mathrm{~s}]$ \\
\hline $\mathrm{G}_{\mathrm{A}}(\mathrm{s})$ & $30 \% ; 12$ & 173,22 & 0,0693 & Fig. 11 & $50^{\circ}$ & 0,5 & $0,43 \mathrm{e}^{-j 120^{\circ}}$ & $2,31 \mathrm{e}^{-j 10^{\circ}}$ & $29,7 \%$ & 0,0584 \\
\hline $\mathrm{G}_{\mathrm{A}}(\mathrm{s})$ & $5 \% ; 12$ & 173,22 & 0,0693 & Fig. 11 & $70^{\circ}$ & 0,8 & $0,19 \mathrm{e}^{-j 165^{\circ}}$ & $5,20 \mathrm{e}^{j 55^{\circ}}$ & $4,89 \%$ & 0,0605 \\
\hline $\mathrm{G}_{\mathrm{B}}(\mathrm{s})$ & $30 \% ; 12$ & 0,3521 & 34,08 & Fig. 11 & $55^{\circ}+45,9^{\circ}$ & 0,35 & $1,03 \mathrm{e}^{-\mathrm{j} 23^{\circ}}$ & $0,97 \mathrm{e}^{-j 56^{\circ}}$ & $18,6 \%$ & 24,78 \\
\hline $\mathrm{G}_{\mathrm{B}}(\mathrm{s})$ & $5 \% ; 12$ & 0,3521 & 34,08 & Fig. 11 & $70^{\circ}+26,2^{\circ}$ & 0,2 & $1,09 \mathrm{e}^{-j 13^{\circ}}$ & $0,92 \mathrm{e}^{-j 71^{\circ}}$ & $0,15 \%$ & 28,69 \\
\hline $\mathrm{G}_{\mathrm{C}}(\mathrm{s})$ & $30 \% ; 20$ & 0,2407 & 83,09 & Fig. 16 & $53^{\circ}+10,1^{\circ}$ & 0,35 & $12,7 \mathrm{e}^{-j 122^{\circ}}$ & $0,08 \mathrm{e}^{\mathrm{j}, 8^{\circ}}$ & $29,6 \%$ & 81,73 \\
\hline $\mathrm{G}_{\mathrm{C}}(\mathrm{s})$ & $20 \% ; 20$ & 0,2407 & 83,09 & Fig. 16 & $62^{\circ}+14,5^{\circ}$ & 0,5 & $8,10 \mathrm{e}^{-j 129^{\circ}}$ & $0,12 \mathrm{e}^{-j 28^{\circ}}$ & $19,7 \%$ & 82,44 \\
\hline
\end{tabular}

Table 10. Summary of required and achieved performance measure values, identification parametres and PID controller tunings for $G_{A}(s), G_{B}(s)$ and $G_{C}(s)$ 


\section{Conclusion}

The proposed new engineering method based on the sine-wave identification of the plant provides successful PID controller tuning. The main contribution has been construction of empirical charts to transform engineering time-domain performance specifications (maximum overshoot and settling time) into frequency domain performance measures (phase margin). The method is applicable for shaping the closed-loop response of the process variable using various combinations of excitation signal frequencies and required phase margins. Using B-parabolas, it is possible to achieve optimal time responses of processes with various types of dynamics and improve their performance. When applying digital PID controller, it is recommended to set the sampling period $T_{\mathrm{s}}$ from the interval

$$
T_{s} \in\left\langle\frac{0,2}{\omega_{c}}, \frac{0,6}{\omega_{c}}\right\rangle
$$

where $\omega_{c}$ is the critical frequency of the controlled plant (Wittenmark, 2001).

By applying appropriate PID controller design methods including the above presented $51+3$ tuning rules for prescribed performance, it is possible to achieve cost-effective control of industrial processes. The presented advanced sine-wave design method offers one possible way to turn the unfavourable statistical ratio between properly tuned and all implemented PID controllers in industrial control loops.

\section{Acknowledgment}

This research work has been supported by the Scientific Grant Agency of the Ministry of Education of the Slovak Republic, Grant No. 1/1241/12.

\section{References}

Åström, K.J. \& Hägglund, T. (1995). PID Controllers: Theory, Design and Tuning (2nd Edition), Instrument Society of America, Research Triangle Park, ISBN 1-55617-516-7

Åström, K.J. \& Hägglund, T. (2000). Benchmark Systems for PID Control. IFAC Workshop on Digital Control PID'00, pp. 181-182, Terrassa, Spain, April, 2000

Bakošová, M. \& Fikar, M. (2008). Riadenie procesov (Process Control), Slovak University of Technology in Bratislava, ISBN 978-80-227-2841-6, Slovak Republic (in Slovak)

Balátě, J. (2004). Automatické ř́zení (Automatic Control) (2nd Edition), BEN - technická literatúra, ISBN 80-7300-148-9, Praha, Czech Republic (in Czech)

Bucz, Š.; Marič, L.; Harsányi, L. \& Veselý, V. (2010). A Simple Robust PID Controller Design Method Based on Sine Wave Identification of the Uncertain Plant. Journal of Electrical Engineering, Bratislava, Vol. 61, No. 3, (2010), pp. 164-170, ISSN 1335-3632

Bucz, Š.; Marič, L.; Harsányi, L. \& Veselý, V. (2010). A Simple Tuning Method of PID Controllers with Prespecified Performance Requirements. 9th International Conference Control of Power Systems 2010, High Tatras, Slovak Republic, May 18-20, 2010 
Bucz, ̌̌.; Marič, L.; Harsányi, L. \& Veselý, V. (2010). Design-oriented Identification Based on Sine Wave Signal and its Advantages for Tuning of the Robust PID Controllers. International Conference Cybernetics and Informatics, Vyšná Boca, Slovak Republic, 2010

Bucz, Š.; Marič, L.; Harsányi, L. \& Veselý, V. (2011). Easy Tuning of Robust PID Controllers Based on the Design-oriented Sine Wave Type Identification. ICIC Express Letters, Vol. 5, No. 3 (March 2011), pp. 563-572, ISSN 1881-803X, Kumamoto, Japan

Bucz, Š. (2011). Engineering Methods of Robust PID Controller Tuning for Specified Performance. Doctoral Thesis, Slovak University of Technology in Bratislava, Slovak Republic (in Slovak)

Coon, G.A. (1956). How to Find Controller Settings from Process Characteristics, In: Control Engineering, Vol. 3, No. 5, (May 1956), pp. 66-76

Chandrashekar, R.; Sree, R.P. \& Chidambaram, M. (2002). Design of PI/PID Controllers for Unstable Systems with Time Delay by Synthesis Method, Indian Chemical Engineer Section A, Vol. 44, No. 2, pp. 82-88

Chau, P.C. (2002). Process Control - a First Course with MATLAB (1 st $^{\text {edition}), ~ C a m b r i d g e ~}$ University Press, ISBN 978-0521002554, New York

Chen, D. \& Seborg, D.E. (2002). PI/PID Controller Design Based on Direct Synthesis and Disturbance Rejection, Industrial Engineering Chemistry Research, 41, pp. 4807-4822

Chien, K.L.; Hrones, J.A. \& Reswick, J.B. (1952). On the Automatic Control of Generalised Passive Systems. Transactions of the ASME, Vol. 74, February, pp. 175-185

Ford, R.L. (1953). The Determination of the Optimum Process-controller Settings and their Confirmation by Means of an Electronic Simulator, Proceedings of the IEE, Part 2, Vol. 101, No. 80, pp. 141-155 and pp. 173-177, 1953

Grabbe, E.M.; Ramo, S. \& Wooldrige, D.E. (1959-61). Handbook of Automation Computation and Control, Vol. 1,2,3, New York

Haalman, A. (1965). Adjusting Controllers for a Deadtime Process, Control Engineering, July

Hang, C.C. \& Åström, K.J. (1988). Practical Aspects of PID Auto-tuners Based on Relay feedback, Proceedings of the IFAC Adaptive Control of Chemical Processes Conference, pp. 153-158, Copenhagen, Denmark, 1998

Harsányi, L.; Murgaš, J.; Rosinová, D. \& Kozáková, A. (1998). Teória automatického riadenia (Control Theory), Slovak University of Technology in Bratislava, ISBN 80-227-1098-9, Slovak Republic (in Slovak)

Hudzovič, P. (1982). Teória automatického riadenia I. Lineárne spojité systémy (Control theory: Linear Continuous-time Systems), Slovak University of Technology in Bratislava, Slovak Republic (in Slovak)

Kozáková, A.; Veselý, V. \& Osuský, J. (2010). Decentralized Digital PID Design for Performance. In: 12th IFAC Symposium on Large Scale Systems: Theory and Applications, Lille, France, 12.-14.7.2010, Ecole Centrale de Lille, ISBN 978-2-915-91326-2

Morari, M., Zafiriou, E. (1989). Robust Processs Control. Prentice-Hall Inc., Englewood Cliffs, ISBN 0137821530, 07632 New Jersey, USA

O’Dwyer, A. (2006). Handbook of PI and PID Controllers Tuning Rule (2nd Edition), Imperial College Press, ISBN 1860946224, London 
Osuský, J.; Veselý, V. \& Kozáková, A. (2010). Robust Decentralized Controller Design with Performance Specification, ICIC Express Letters, Vol. 4, No. 1, (2010), pp. 71-76, ISSN 1881-803X, Kumamoto, Japan

Pettit, J.W. \& Carr, D.M. (1987). Self-tuning Controller, US Patent No. 4669040

Rotach, V. (1984). Avtomatizacija nastrojki system upravlenija. Energoatomizdat, Moskva, Russia (in Russian)

Rotach, V. (1994). Calculation of the Robust Settings of Automatic Controllers, Thermal Engineering (Russia), Vol. 41, No. 10, pp. 764-769, Moskva, Russia

Suyama, K. (1992). A Simple Design Method for Sampled-data PID Control Systems with Adequate Step Responses, Proceedings of the International Conference on Industrial Electronics, Control, Instrumentation and Automation, pp. 1117-1122, 1992

Veselý, V. (2003). Easy Tuning of PID Controller. Journal of Electrical Engineering, Vol. 54, No. 5-6, (2003), pp. 136-139, ISSN 1335-3632, Bratislava, Slovak Republic

Visioli, A. (2001). Tuning of PID Controllers with Fuzzy Logic, IEE Proceedings-Control Theory and Applications, Vol. 148, No. 1, pp. 180-184, 2001

Visoli, A. (2006). Practical PID Control, Advances in Industrial Control, Springer-Verlag London Limited, ISBN 1-84628-585-2

Vítečková, M. (1998). Seř́zení regulátorů metodou požadovaného modelu (PID Controllers Tuning by Desired Model Method), Textbook, VŠB - Technical University of Ostrava, ISBN 80-7078-628-0, Czech Republic (in Czech)

Vítečková, M. (1999). Seřízení číslicových i analogových regulátorů pro regulované soustavy s dopravním zpožděním (Tuning Discrete and Continuous Controllers for Processes with Time Delay). Automatizace, Vol. 42, No. 2, (1999), pp. 106-111, Czech Republic (in Czech)

Vítečková, M.; Víteček, A. \& Smutný, L. (2000). Controller Tuning for Controlled Plants with Time Delay, Preprints of Proceedings of PID'00: IFAC Workshop on Digital Control, pp. 83-288, Terrassa, Spain, April 2000

Wang, L. \& Cluett, W.R. (1997). Tuning PID Controllers for Integrating Processes, IEE Proceedings - Control Theory and Applications, Vol. 144, No. 5, pp. 385-392, 1997

Wang, Y.-G. \& Shao, H.-H. (1999). PID Autotuner Based on Gain- and Phase-margin Specification, Industrial Engineering Chemistry Research, 38, pp. 3007-3012

Wittenmark, B. (2001). A Sample-induced Delays in Synchronous Multirate Systems, European Control Conference, Porto, Portugal, pp. 3276-3281, 2001

Wojsznis, W.K.; Blevins, T.L. \& Thiele, D. (1999). Neural Network Assisted Control Loop Tuner, Proceedings of the IEEE International Conference on Control Applications, Vol. 1, pp. 427-431, USA, 1999

Xue, D.; Chen, Y. \& Atherton, D.P. (2007). Linear Feedback Control. Analysis and Design with MATLAB, SIAM Press, ISBN 978-0-898716-38-2

$\mathrm{Yu}$, Ch.-Ch. (2006). Autotuning of PID Controllers. A Relay Feedback Approach (2nd Edition), Springer-Verlag London Limited, ISBN 1-84628-036-2

Ziegler, J.G. \& Nichols, N.B. (1942). Optimum Settings for Automatic Controllers, ASME Transactions, Vol. 64 (1942), pp. 759-768 
Zhuang, M. \& Atherton, D.P. (1993). Automatic Tuning of Optimum PID Controllers, IEE Proceedings, Part D: Control Theory and Applications, Vol. 140, No. 3, pp. 216-224, ISSN 0143-7054, 1993 


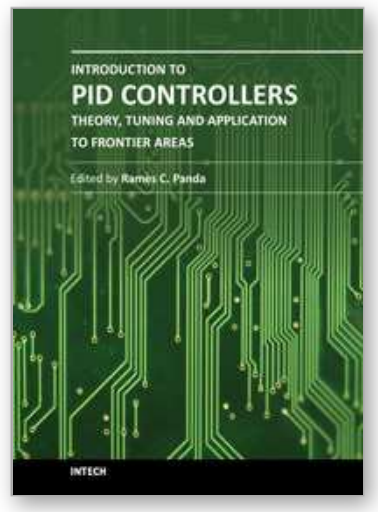

\author{
Introduction to PID Controllers - Theory, Tuning and Application to \\ Frontier Areas \\ Edited by Prof. Rames C. Panda
}

ISBN 978-953-307-927-1

Hard cover, 258 pages

Publisher InTech

Published online 29, February, 2012

Published in print edition February, 2012

This book discusses the theory, application, and practice of PID control technology. It is designed for engineers, researchers, students of process control, and industry professionals. It will also be of interest for those seeking an overview of the subject of green automation who need to procure single loop and multi-loop PID controllers and who aim for an exceptional, stable, and robust closed-loop performance through process automation. Process modeling, controller design, and analyses using conventional and heuristic schemes are explained through different applications here. The readers should have primary knowledge of transfer functions, poles, zeros, regulation concepts, and background. The following sections are covered: The Theory of PID Controllers and their Design Methods, Tuning Criteria, Multivariable Systems: Automatic Tuning and Adaptation, Intelligent PID Control, Discrete, Intelligent PID Controller, Fractional Order PID Controllers, Extended Applications of PID, and Practical Applications. A wide variety of researchers and engineers seeking methods of designing and analyzing controllers will create a heavy demand for this book: interdisciplinary researchers, real time process developers, control engineers, instrument technicians, and many more entities that are recognizing the value of shifting to PID controller procurement.

\title{
How to reference
}

In order to correctly reference this scholarly work, feel free to copy and paste the following:

Štefan Bucz and Alena Kozáková (2012). PID Controller Design for Specified Performance, Introduction to PID Controllers - Theory, Tuning and Application to Frontier Areas, Prof. Rames C. Panda (Ed.), ISBN: 978-953307-927-1, InTech, Available from: http://www.intechopen.com/books/introduction-to-pid-controllers-theorytuning-and-application-to-frontier-areas/pid-controller-design-for-specified-performance

\section{INTECH}

open science | open minds

\section{InTech Europe}

University Campus STeP Ri

Slavka Krautzeka 83/A

51000 Rijeka, Croatia

Phone: +385 (51) 770447

Fax: +385 (51) 686166

www.intechopen.com

\section{InTech China}

Unit 405, Office Block, Hotel Equatorial Shanghai

No.65, Yan An Road (West), Shanghai, 200040, China

中国上海市延安西路 65 号上海国际贵都大饭店办公楼 405 单元

Phone: +86-21-62489820

Fax: $+86-21-62489821$ 
(C) 2012 The Author(s). Licensee IntechOpen. This is an open access article distributed under the terms of the Creative Commons Attribution 3.0 License, which permits unrestricted use, distribution, and reproduction in any medium, provided the original work is properly cited. 